\author{
التحديات التي تواجه تطبيق الأساليب الحديثة

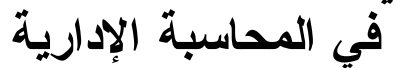 \\ دراسة لآراء عينةٌ من المحاسبين في مدينة الموصل$$
\text { مدرس مساعد- قسم المئمبة }
$$$$
\text { كلية الإدارة والاقتصاد- جامعة الموصل }
$$ \\ Muthanaalzaidy@yahoo.com
}

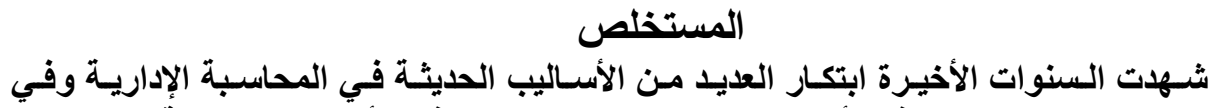

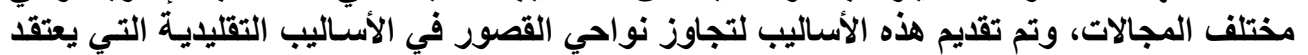

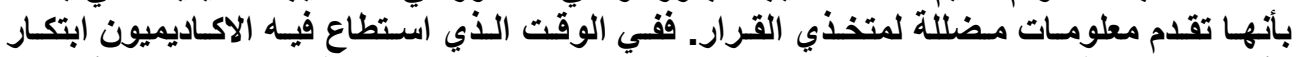

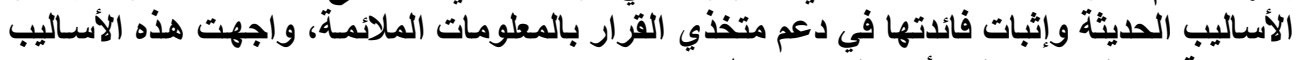
مجموعة من التحديات التي أدت إلى فئل عدم تطبيقها.

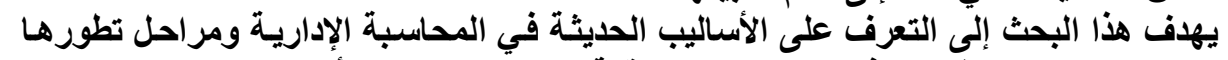

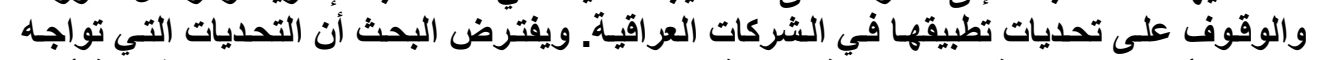

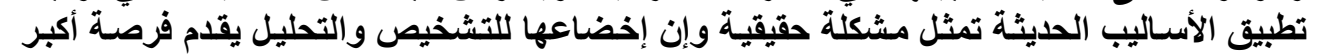

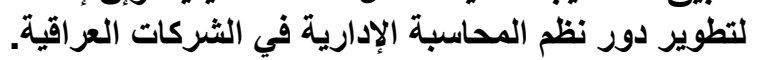

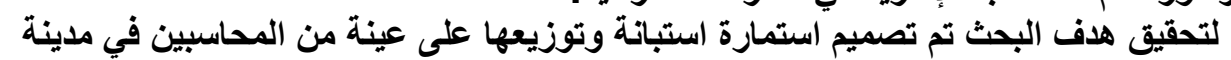

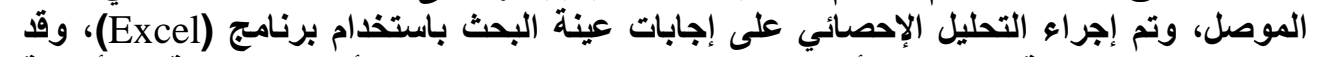

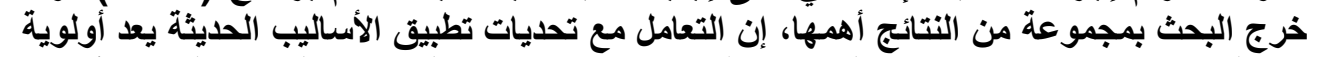

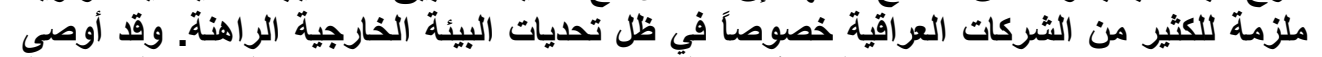

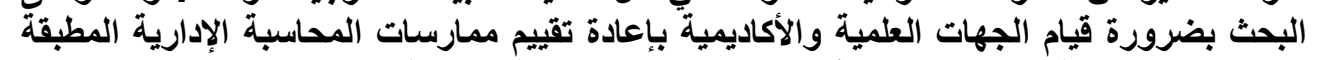

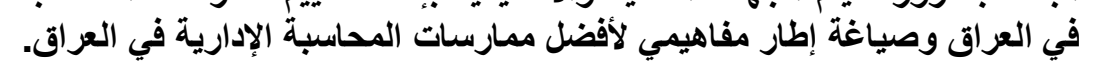

تأريخ قبول النشر 2008/12/23

تأريخ استلام البحث 2008/10/9 


\title{
The Challenges Facing the Application of Modern Management Accounting Techniques Studying for The Opinion a Sample of Accountants in the City of Mosul
}

\author{
Muthana F. Al-Zaidy \\ Assistant Lecturer \\ Collage of Administration and Economics \\ Muthanaalzaidy@yahoo.com
}

\begin{abstract}
The present research aims at identifying modern techniques of management accounting, showing the stages of their development and identifying the challenges that prevent their application in Iraqi companies. The research hypothesizes that these challenges represent a real problem, and make them subject of diagnostic analysis to provide a greater opportunity to develop the role of management accounting systems. To achieve the goal of the research, a survey form has been designed and distributed to a sample of accountants in the City of Mosul, and then statistical analysis of responses has been made to investigate the samples using (Excel). The basic conclusion of the research is to deal with the challenges of the application of modern techniques and binding to many Iraqi companies especially in the light of the challenges of the current external environment. The research recommended the need for the scientific and academic reevaluation of management accounting practices applied in Iraq and drafting a conceptual framework for a better management accounting practices.

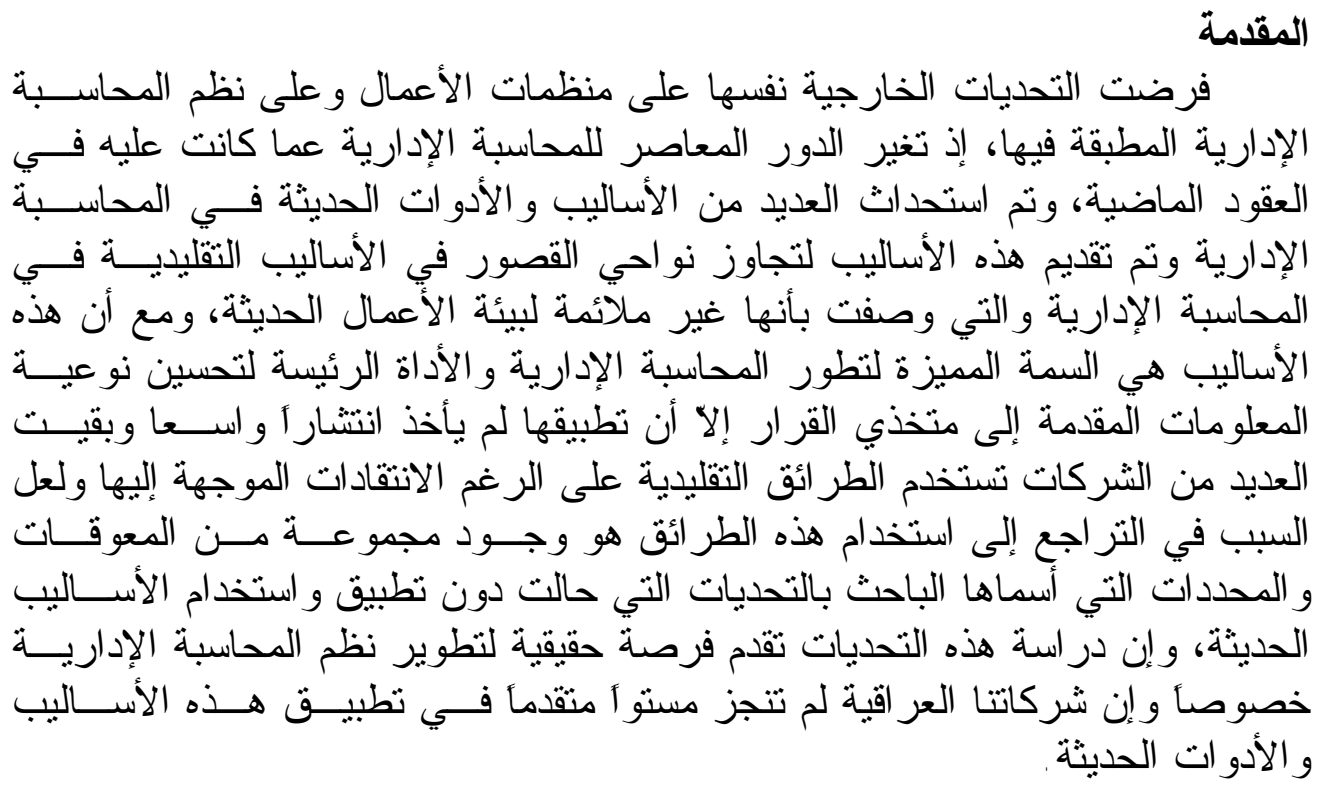


يمكن صياغة مشكلة البحث من خلال طرح التساؤ لات الآتية:

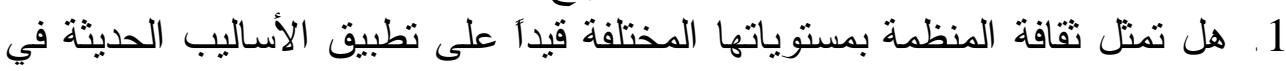
المحاسبة الإدارية في الثركات العر اقية؟

2. هل تتسجم الخبر ات العلمية و العملية التي يمتلكها المحاسب في الثركات العر اقية

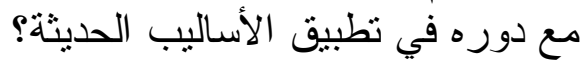
3. هل تبرر القيمة التي سوف تضيفها الأدوات و الأساليب الحديثة على أداء الثركات العر اقية النفقات اللازمة لتطبيقها؟ 4. هل تحتاج الثركات العر اقية إلى إطار مفاهيمي لممارسات المحاســبة الإداريــة

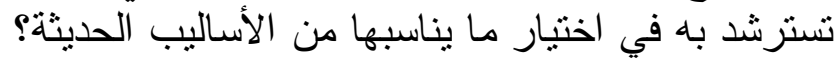

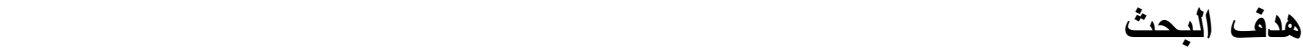
يهذف هذا البحث إلى التعرف على الأساليب الحديثة في المحاسـبـة الإداريــة

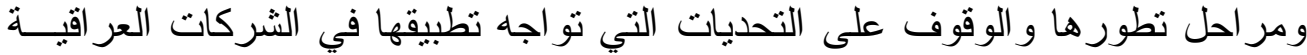
وبيان المسببات الحقيقية لها.

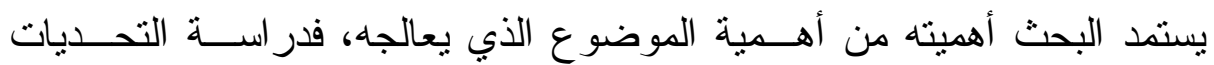

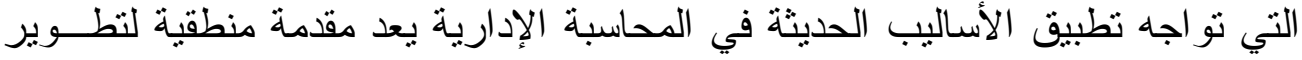

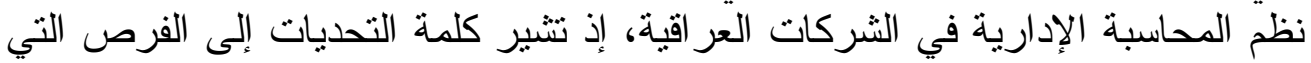
يمكن من خلالها تطوير نظم المحاسبة الإدارية، و الانتقال بها إلى مر احل متقدمة تسهر في تعزيز أداء الثركات العر اقية.

يقوم البحث على فرضية رئيسة مفادها أن التحديات التي تو اجه تطبيق الأساليب فرضية البحث

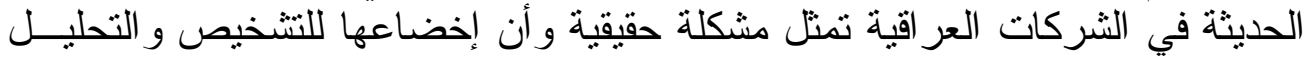

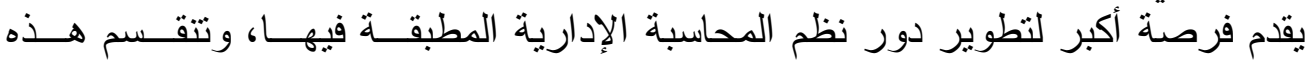
الفرضية إلى عدة فرضيات هي: ألفئ

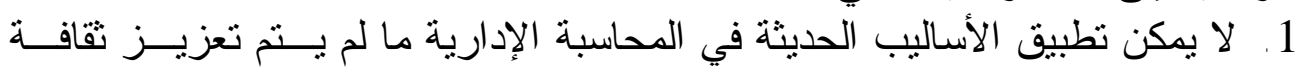
التغيير في الثركات العر اقية.

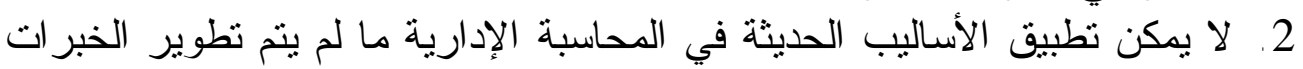

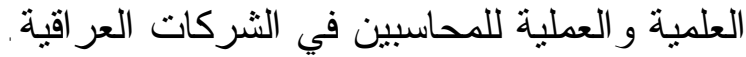




\section{الزيدي [312]}

3. لا يمثل تطبيق الأساليب الحديثة في المحاسبة الإدارية أولوية لكثير من الثركات

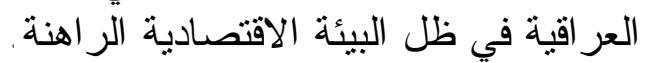

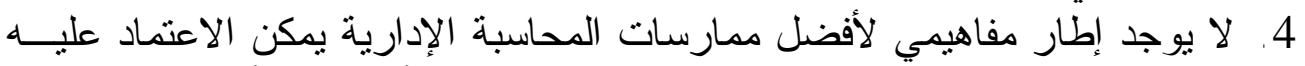
في اختيار ما يتلاءم مع حاجة الثركات العر اقية من الأدو ات و الأساليب الحديثة الأبن.

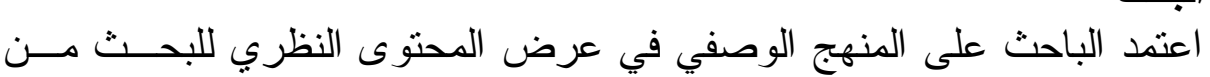

\section{منهج البحث}

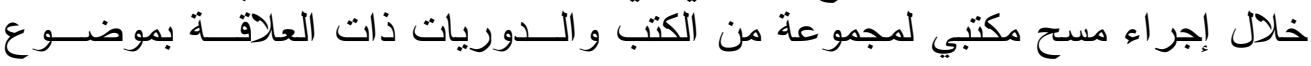

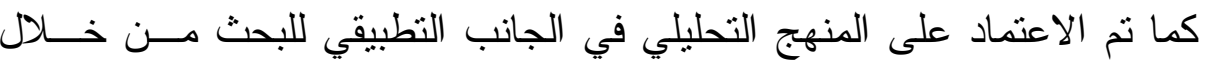

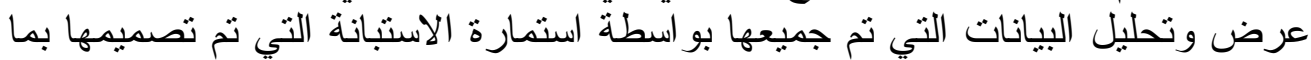

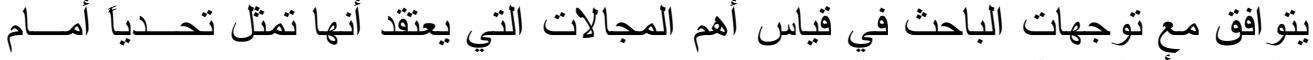

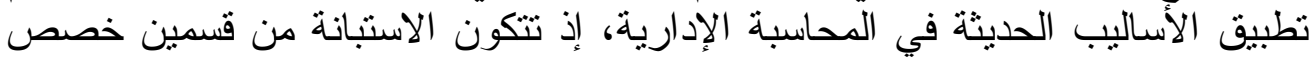

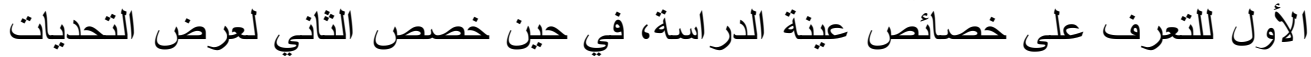

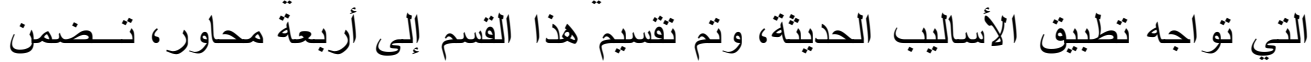

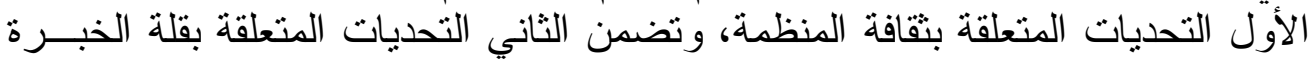

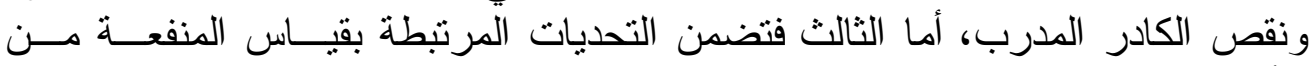
الأساليب الحديثة، في حين تضمن الرابع التحديات المتعلقة بملاءمة بحوث المحاســــة

شملت عينة البحث در اسة لآر اء عينة من المحاسبين في مدينة الموصل بكافــة

\section{عينة البحث}

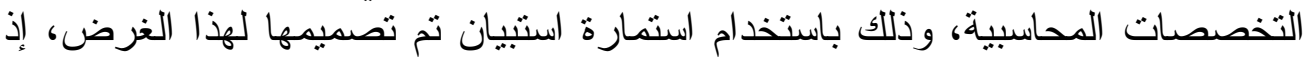

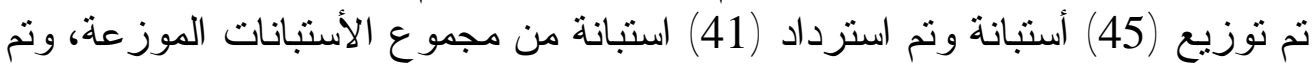

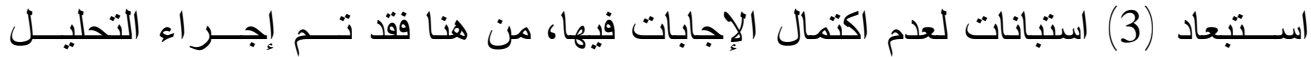

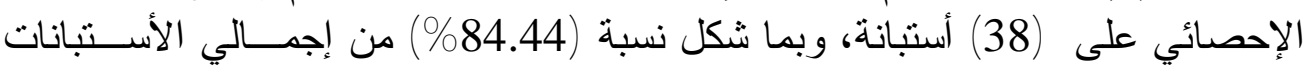
الموزعة.

\section{حدود البحث}

1. إن البحث الحالي مقيد بهدف محدد هو بيان التحديات التي تواجه تطبيق الأساليب

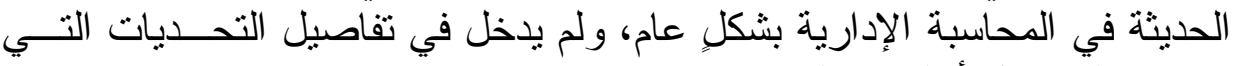
تو اجه تطبيق كل أسلوب على حدة. 
2. لم يتطرق البحث الحالي إلى بيئة و عمليات و أهداف الثركة (الإطـــار المـــوقفي)

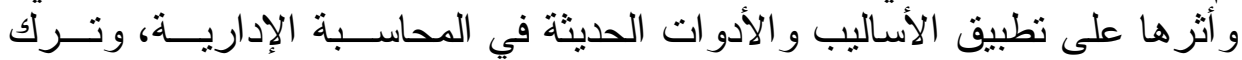

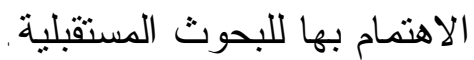

هيكلية البحث: تم تقسيم البحث على المحاور الرئيسة الآتية: - الحاجة إلى تطور المحاسبة الإدارية. - مر احل تطور المحاسبة الإدارية.

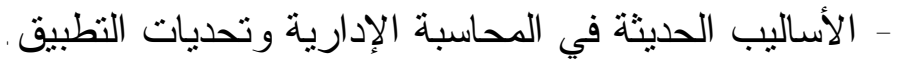
- عرض نتائج الاستبانة وتحليلها.

\section{الحاجة إلى تطور المحاسبة الإدارية}

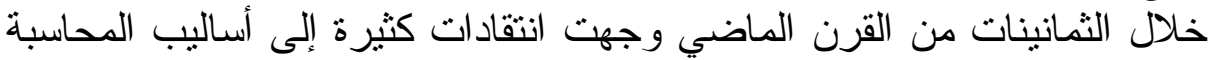

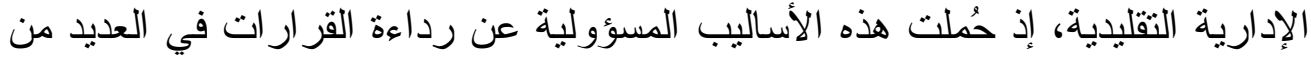

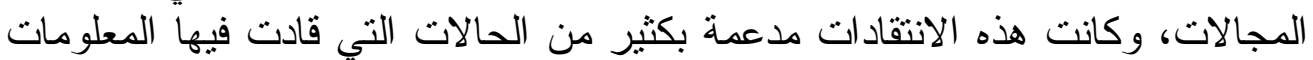

المحاسبية مدر اء الثركات لاتخاذ قر ار ات خاطئة (Dimnik \& Kuder,1989,12).

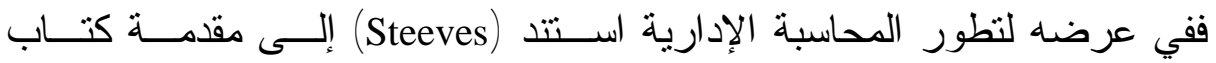

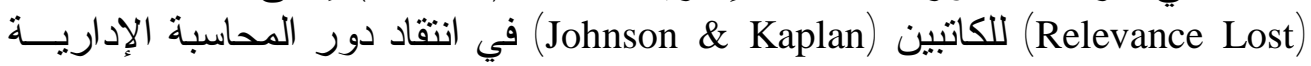

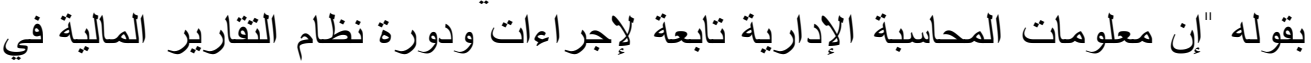

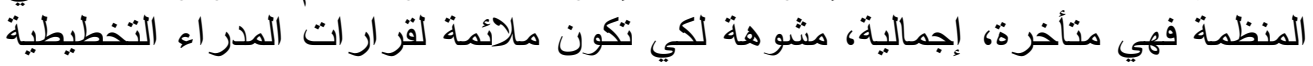

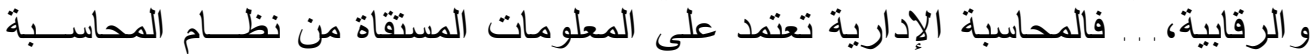

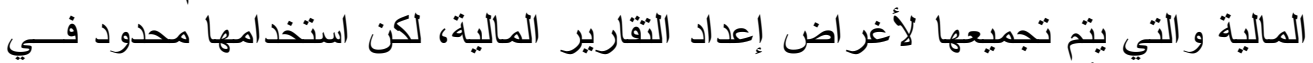
مجال قياس الأداء و الرقابة المنظمية" (Steeves, 1990, 17) .

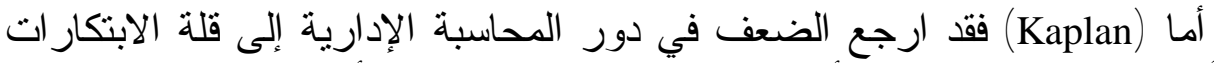

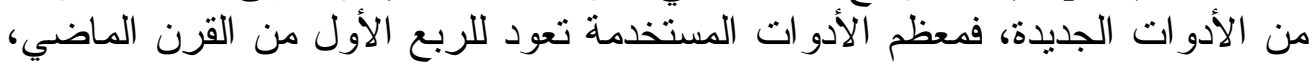

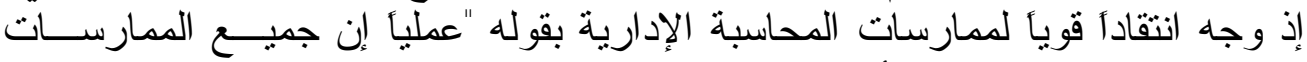

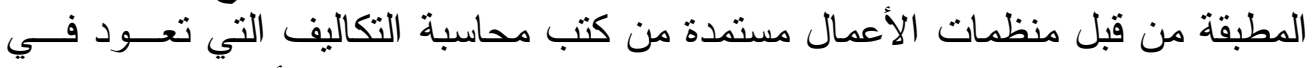

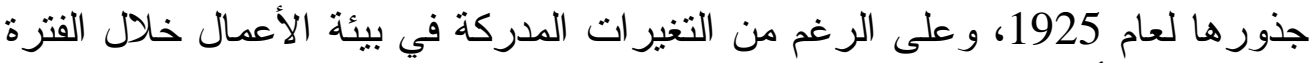

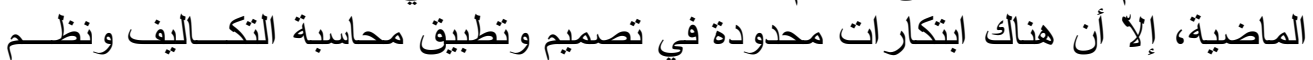

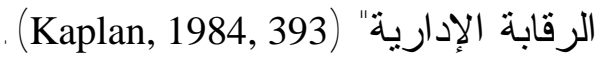

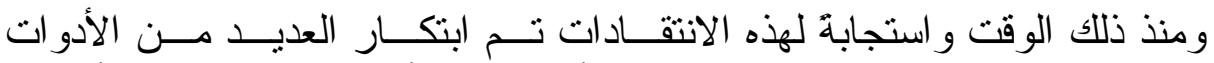

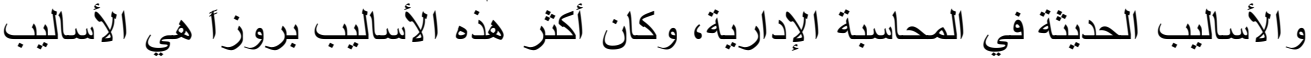

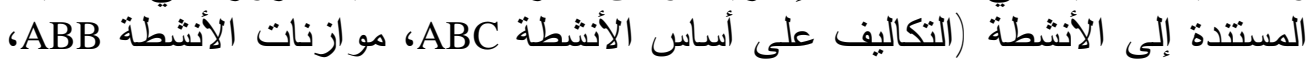




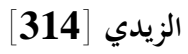

الإدارة على أساس الأنشطة ABM)، و المقارنة المرجعية (Benchmarking)، وبطاقــة

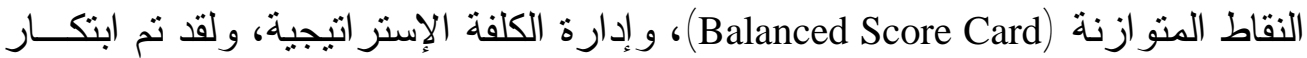

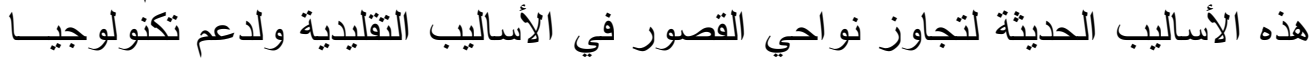

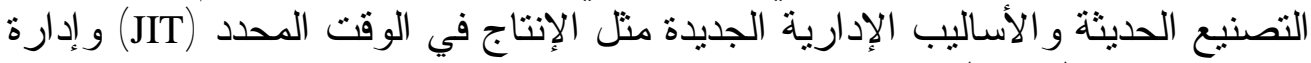

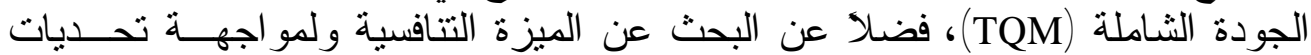

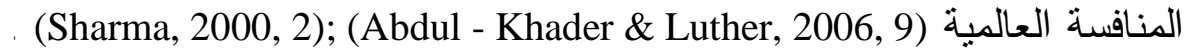

مر احل تطور المحاسبة الإدارية

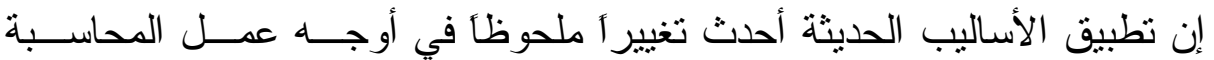

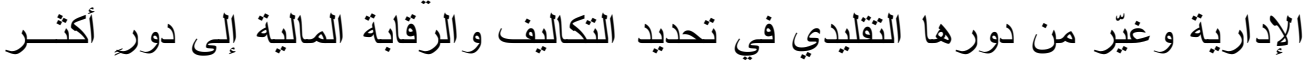

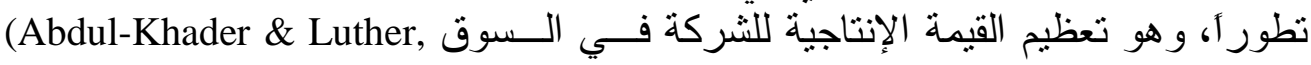
.2006, 9)

وللوقوف على الأسباب التي أدت إلىى هذا التغيير قدمت لجنـــة الإدارة الماليــة

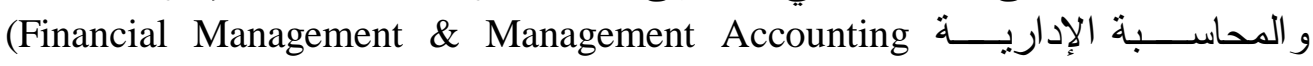
التابعة للاتحاد الدولي للمحاسبين Committee (FMAC))

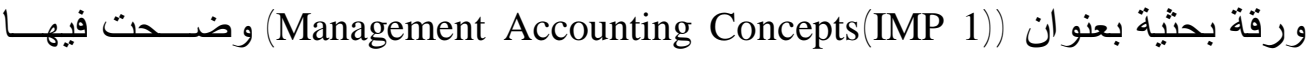

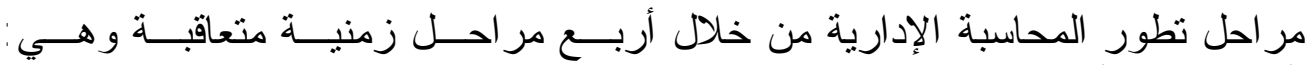
(IFAC, 1998)

\section{المرحلة الأولى: (ما قبل سنة 1950) تحديد التكاليف والرقابة المالية}

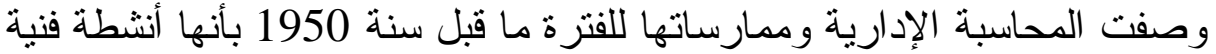

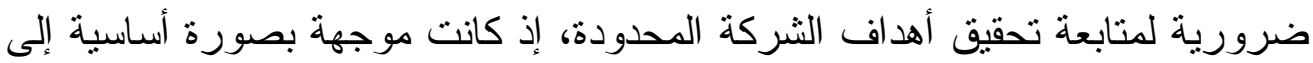

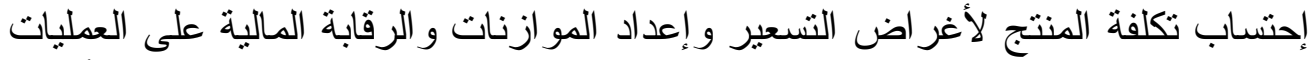

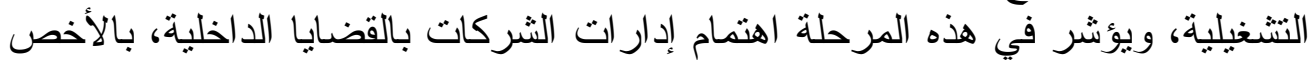

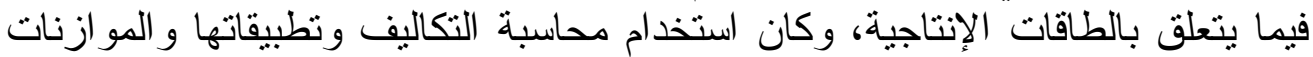

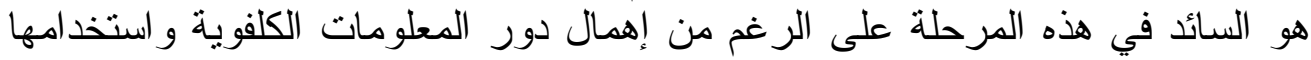

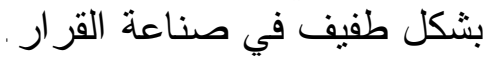

المرحلة الثانية: (من سنة1950 - لغاية سنة 1965) تــوفير المعلومــات لأغـراض التخطيط و الرقابة التمابة

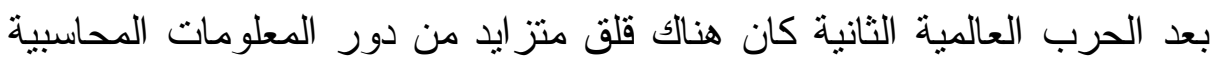
بشكل عام و المعلومات التكاليفية بشكل خاص، ومدى ملاصن ملاعمتها لاحتياجات المستخدمين،

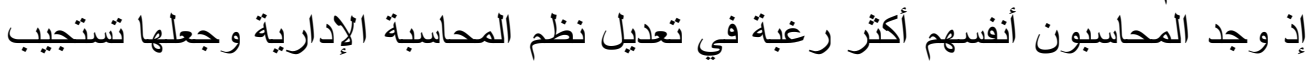


لاحتياجات الإدارة، ففي تلك الفترة تغير اهتمام المحاسبة الإدارية و أزداد تركيزها على الإدي

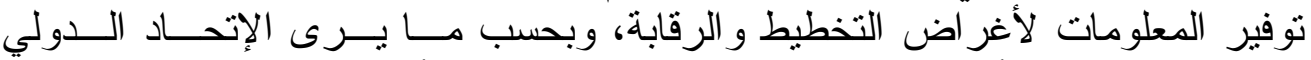

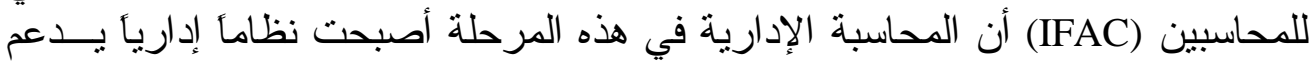

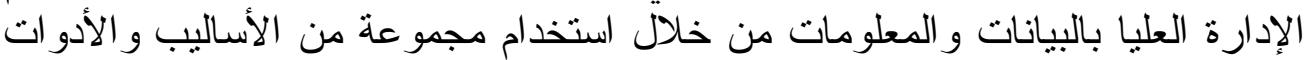

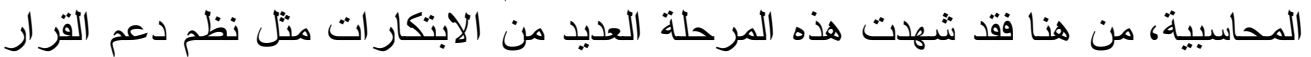

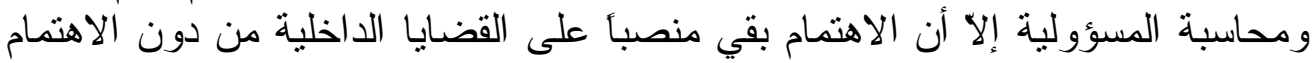

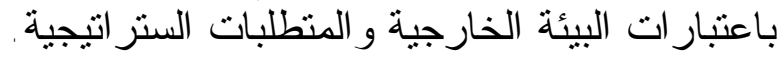

\section{المرحلة الثالثة: (من سنة 1965 - لغاية سنة 1985) تخفيض الضياع والهدر فـي الموارد}

خلال السبعينات من القرن الماضي واجهت منظمات الأعمال تحديات كبيــرة،

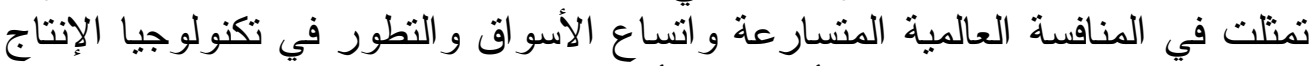

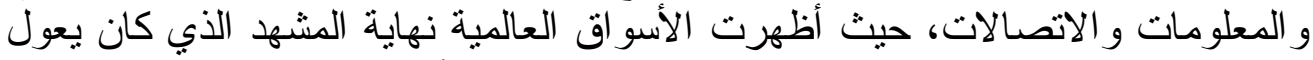

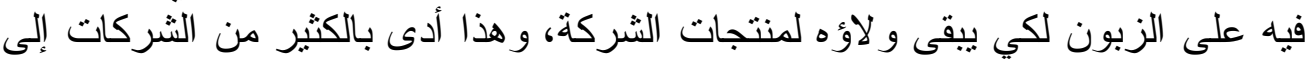

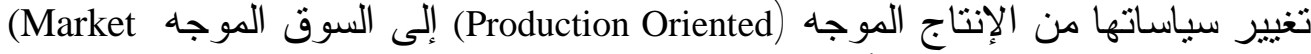

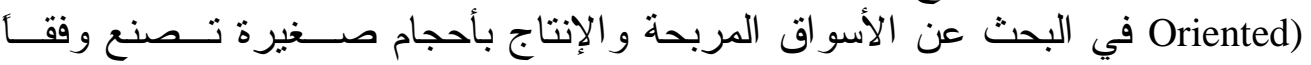
لاحتياجات الزبون (Ning, 2005, 25).

لقد أدى هذا التغير إلى توسيع قاعدة المتطلبات التقنية و الفنية و التي أدت بدور ها

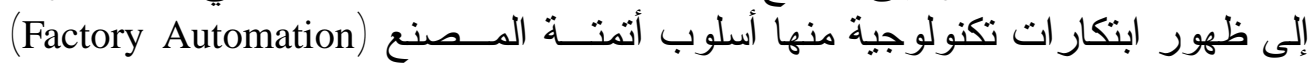

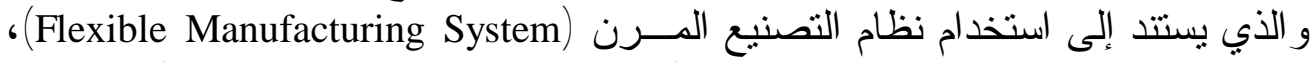

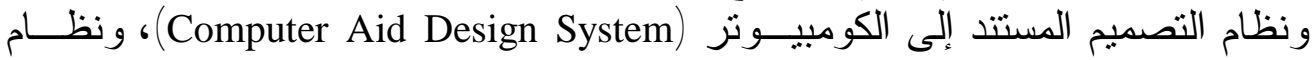

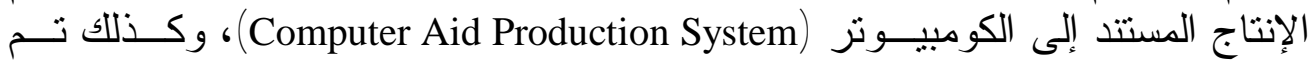
استحداث أساليب إنتاج جديدة ترنكز على درجة التقيد التقني مثل أسلوب الإنتاج فـي

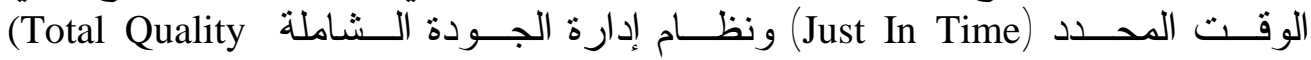
(Ning, 2005, و التي تركز على تخفيض الضياع و الهدر في المــو اردة Management) (Atkinson, 1989, 35) 25)

لقد فرضت هذه التحديات نفسها على منظمات الأعمال و على نظــــ المحاســبة

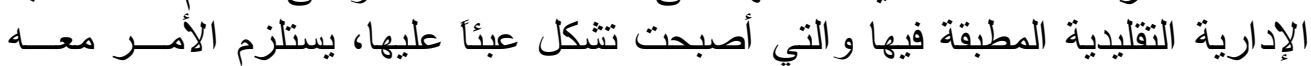

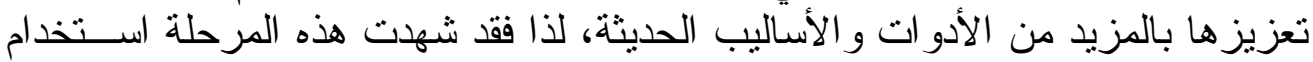

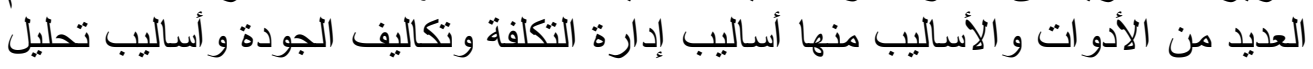




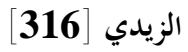

\section{المرحلة الرابعة: (من سنة 1985 - لحد الآن) تعظيم القيمة من خــلل الاســـذام

\author{
الأمثل للموارد
}

منذ بداية النصف الثاني من الثمانينات من القرن الماضي وحتى اليوم لم تــزل الإل

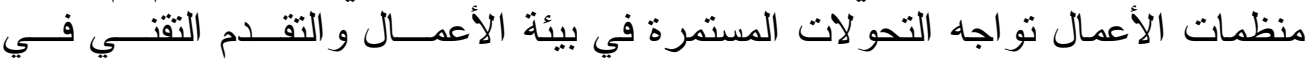

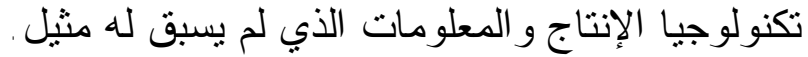

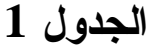

مر احل تطور أدوات وأساليب المحاسبة الإدارية

\begin{tabular}{|c|c|c|c|c|}
\hline 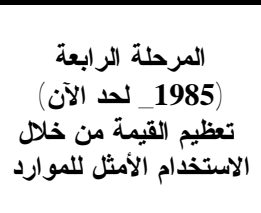 & 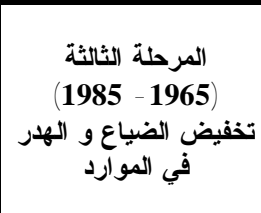 & 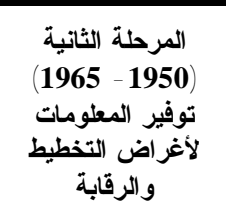 & 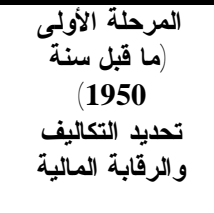 & 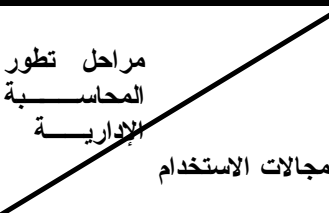 \\
\hline 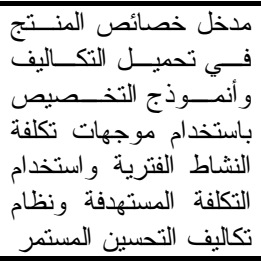 & 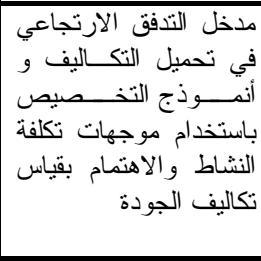 & 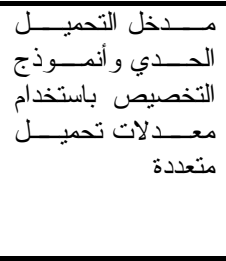 & 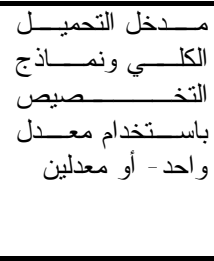 & مجال قياس التكاليف \\
\hline 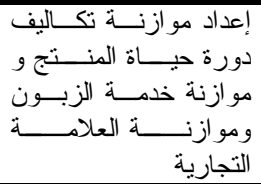 & وإعداد موازنات الجودة الأنشطة & 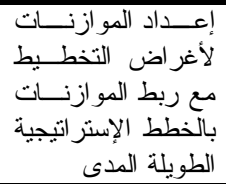 & 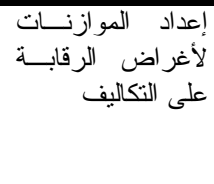 & 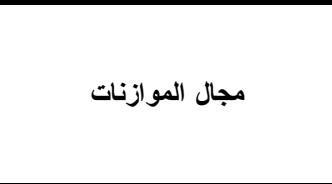 \\
\hline 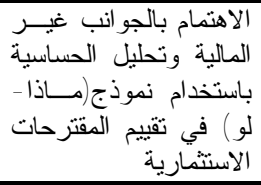 & 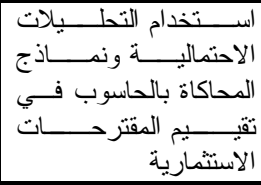 & 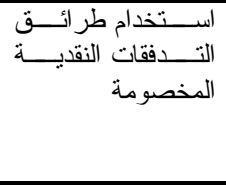 & 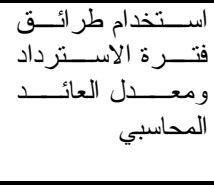 & مجال الموازنات الرأسمالية \\
\hline 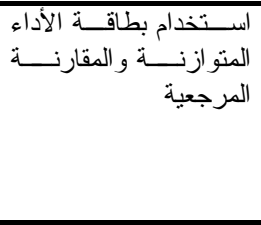 & 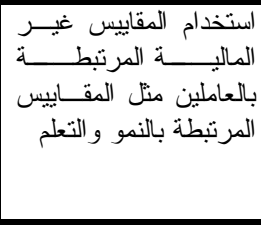 & 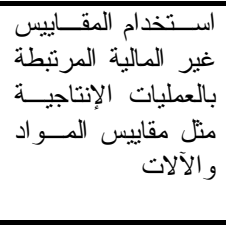 & 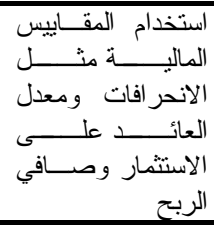 & مجال الرقابة التشغيلية وتقييم \\
\hline 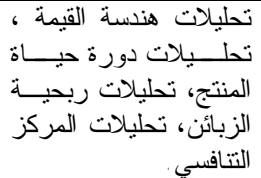 & 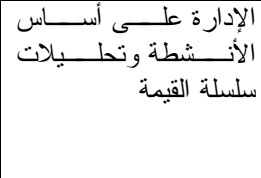 & 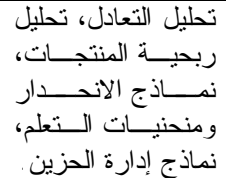 & 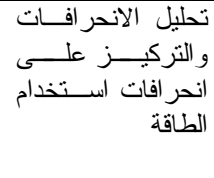 & مجال دعم القرار \\
\hline
\end{tabular}


فعلى سبيل المثال إن الاستخدام الواسع لشبكة الانترنت أدى إلى ظهور التجارة

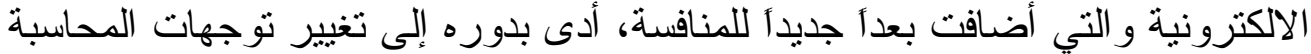

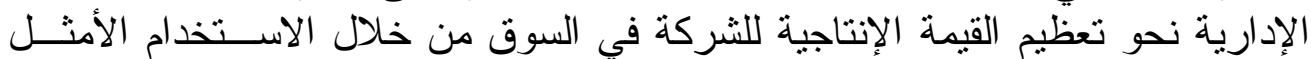

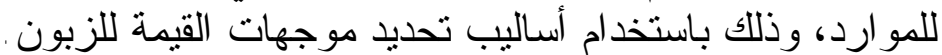

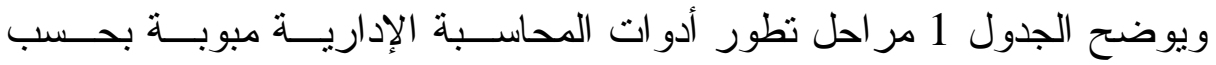
مجالات استخدام المحاسبة الإدارية في المنظمة.

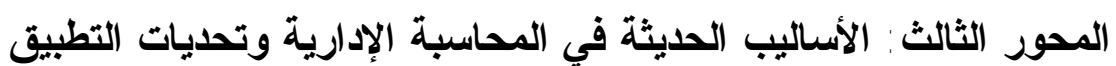

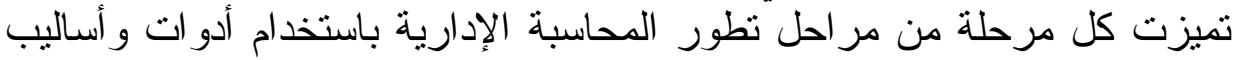

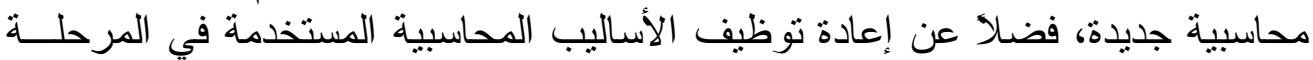

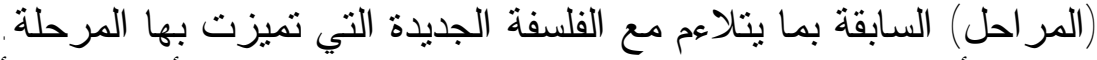

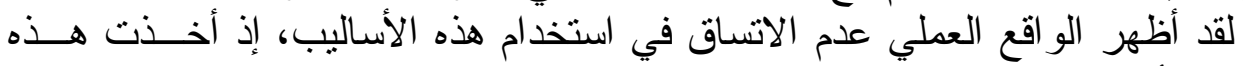

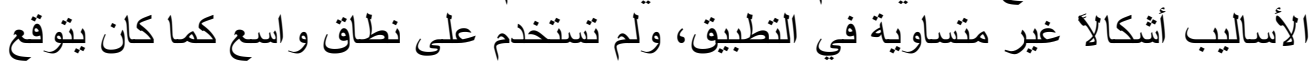

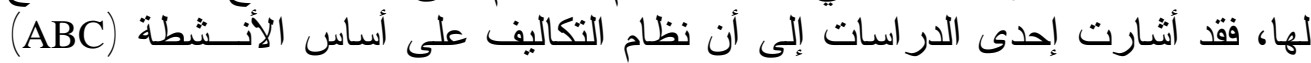

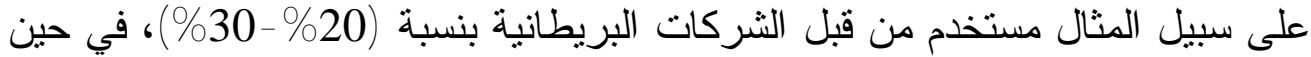

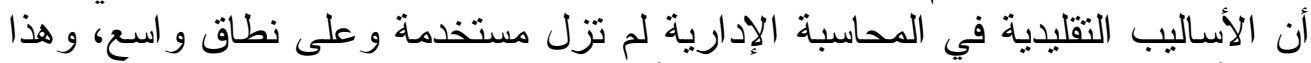

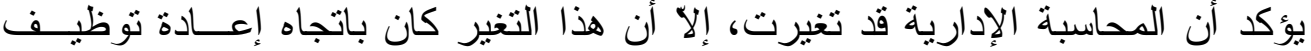

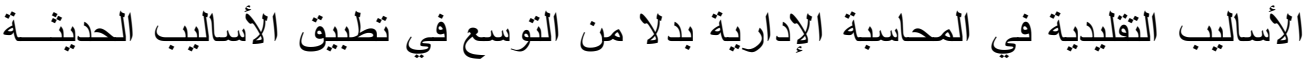
(بتصرف (Burns,2000,2) (Steeves,1990,18) و هذا يقودنا إلى التساؤل لماذا تتغير المحاسبة الإدارية ببطئ شديد ور اء التغير ات

المتسار عة في بيئة الأعمال الحديثة؟ الفئ

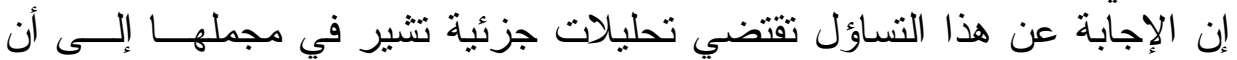

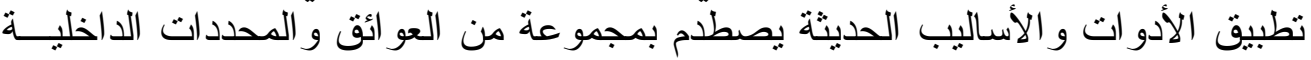

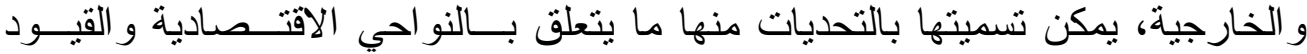

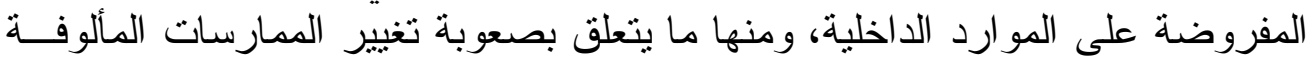
التي قد تحول دون تطبيق هذه الأدوات و الأساليب و التي يمكن عرضها باتئ بالثكل الآتي:

أ. المنظمة وثقافة التغيير

إن تطبيق الأساليب و الأدو ات الحديثة بتطلب خلق التق البيئة التي يقتنع فيها الأفر اد في

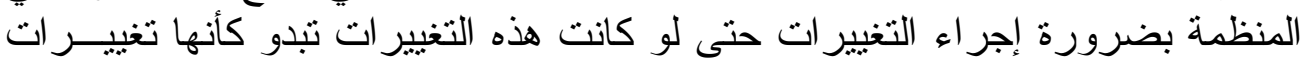

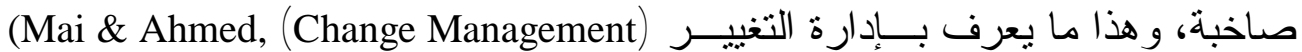




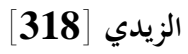

و هنا يمكن تحديد ثلاثة مستويات من التحديات المرتبطة بثقافة المنظمة التي تو اجه تطبيق الأساليب الحديثة و هي (www.esnips.com/search/costaccounting) :

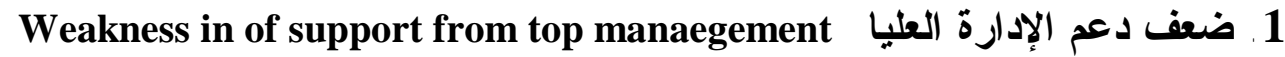

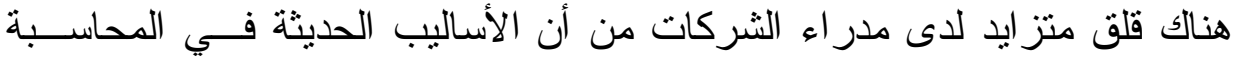

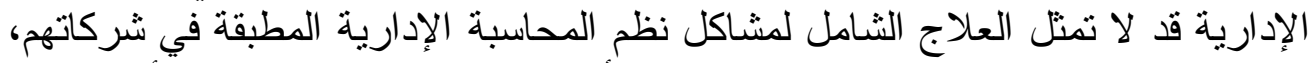

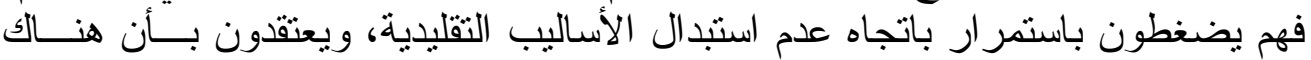

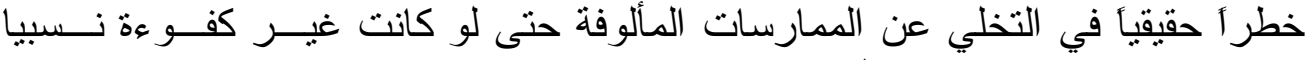
. (Dimnik \& Kuder,1989,14)"

ومن جانب آخر فإن المختصين في المحاسبة الإدارية يتحركون باتجاه مــشاركة

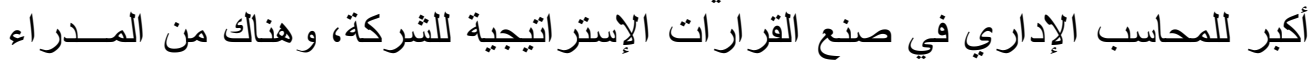

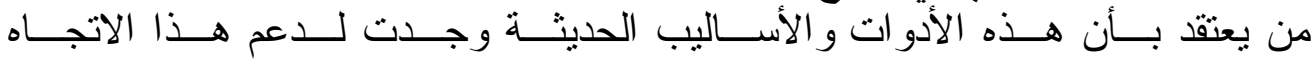
(Steeves,1990,18)

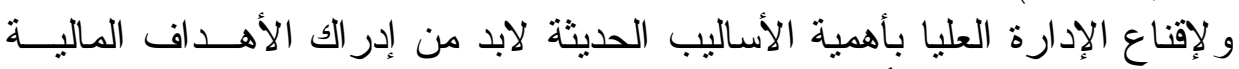

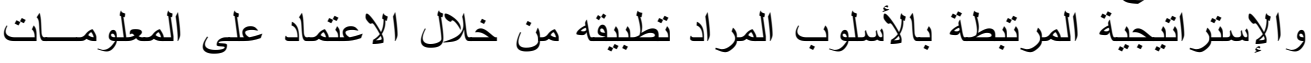

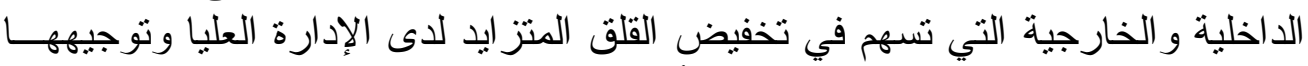

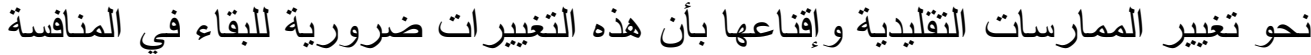
. (Mai \& Ahmed,2005,46)

2. معارضة الكادر المحاسبي للتغيير \&esistance from Staff to change

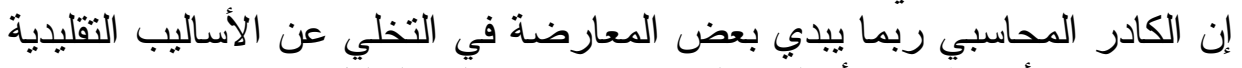

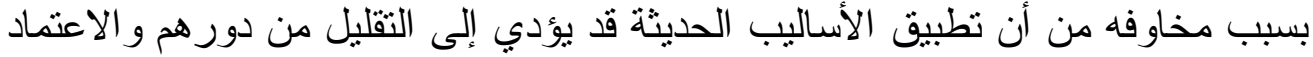

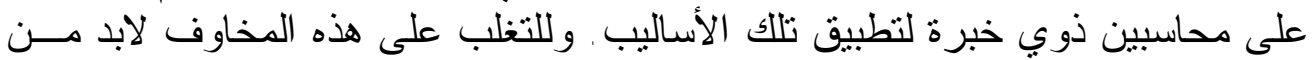

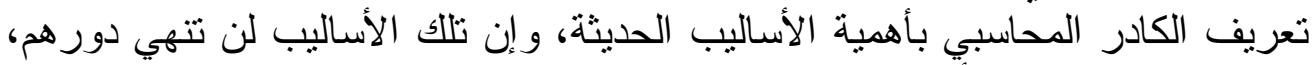

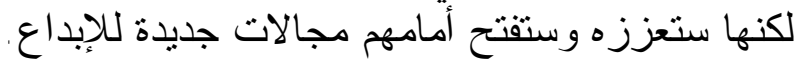

3.عدم تعاون المستويات الأخرى Non-cooperation at other levels

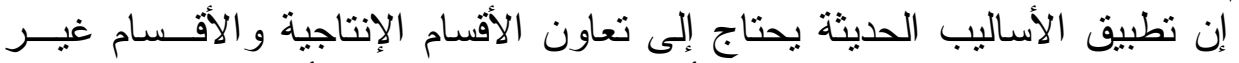

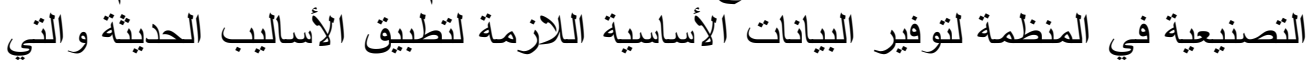

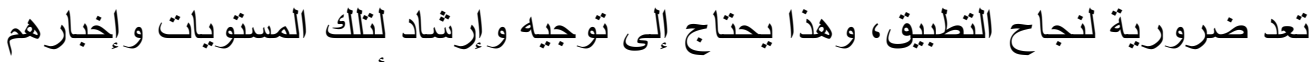

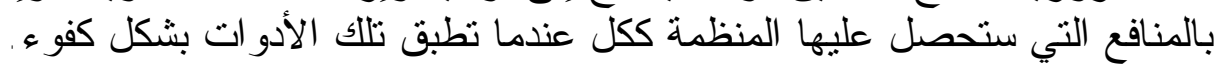

ب. قلة الخبرة لاى المحاسبين الإداريين ونقص الكادر المدرب

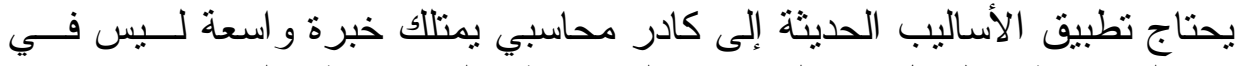
الجوانب المحاسبية فقط، بل في المجالات التصنيعية و التـسويقية و المجــالات غيــر 


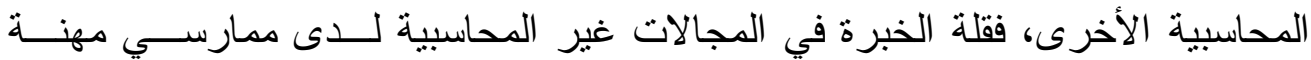

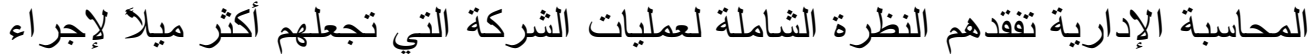
التغيير ات في نظم المحاسبة الإدارية وتعزيز ها بالمزيد من الأساليب و الأدوات التهات الحديثة . (Mai \& Ahmed, 2005, 48) (Sheildes, et.al,1991, 72)

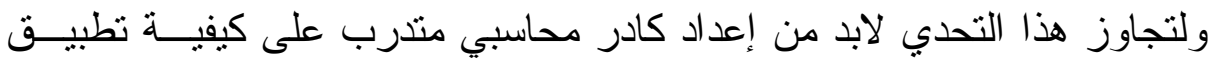

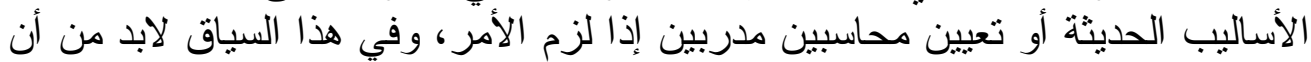

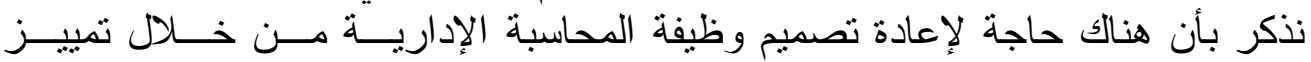

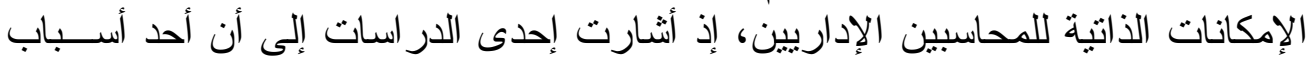

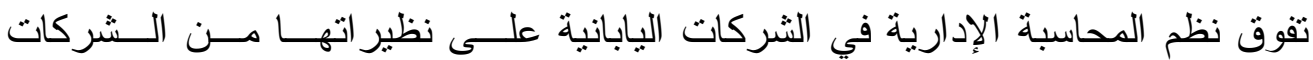

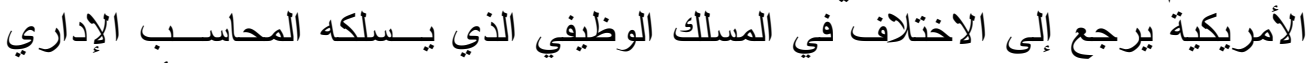
ومحاسب التكاليف في كلا البلدين، فمعظم محاسبي التكاليف في الثركات فئ الأمريكية ينت

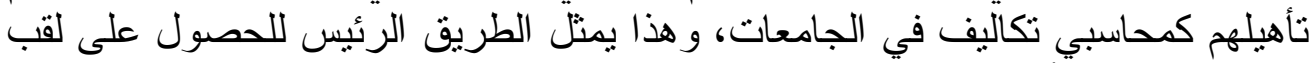

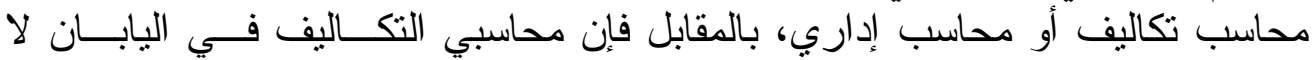

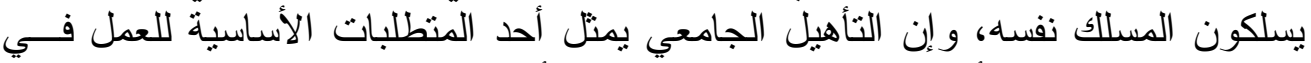

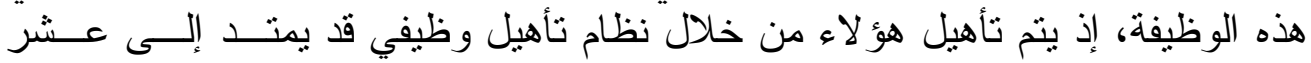

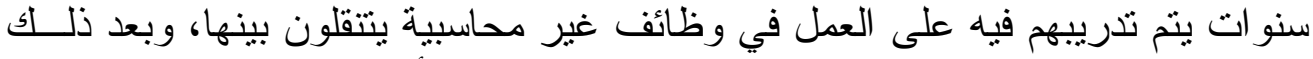

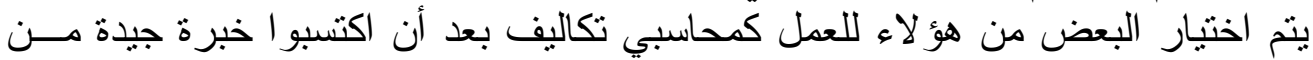
الأقسام التي عملو ا بها (Shields, et.al, 1991, 72).

ت. قياس المنفعة للأدوات الحديثة

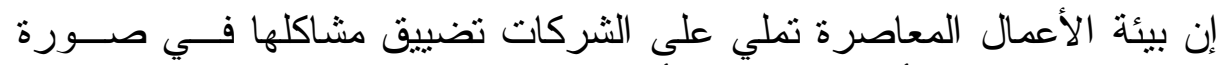

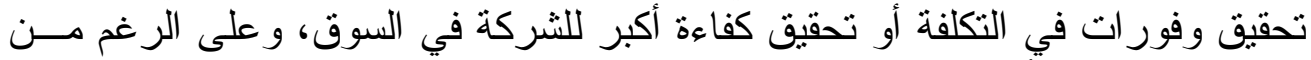

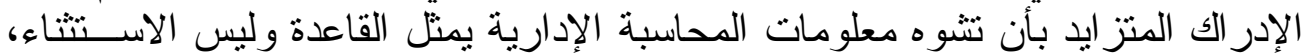

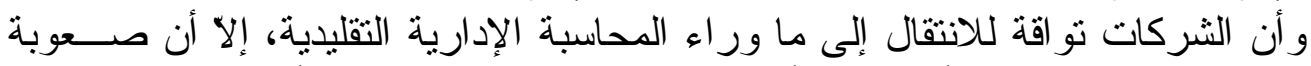

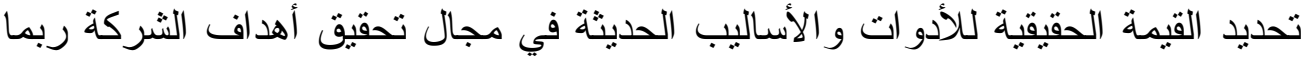

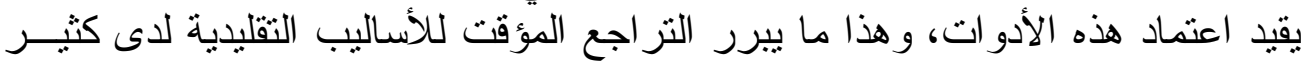
من الثركات (Garg, et.al, 2003, 32) .

ث. بحوث المحاسبة الإدارية

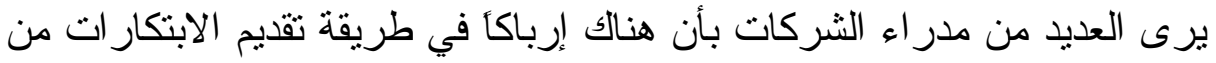

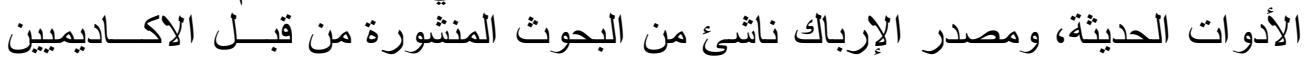
و المنظمات المختصة في المحاسبة الإدارية، إذ يحاول كل منهم تقديم الأسلوب المبنكر 


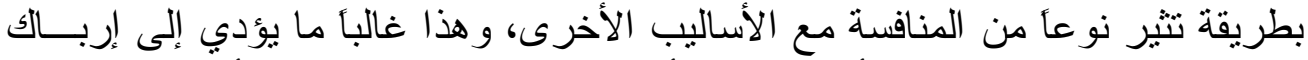

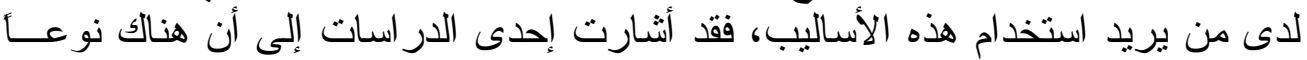

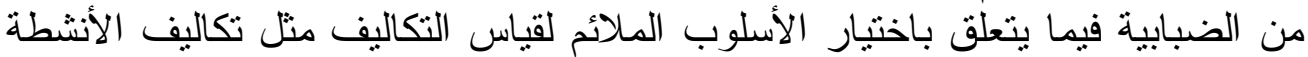

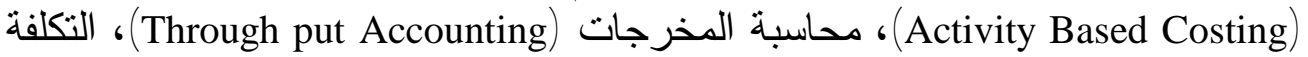

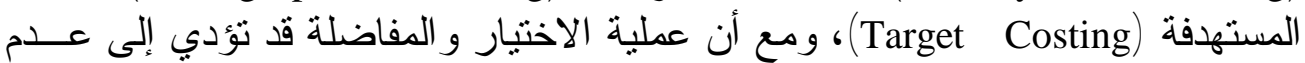

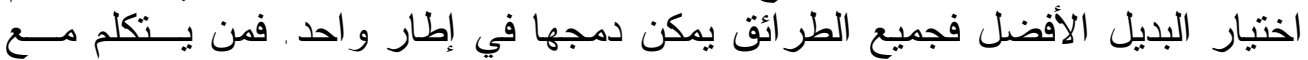

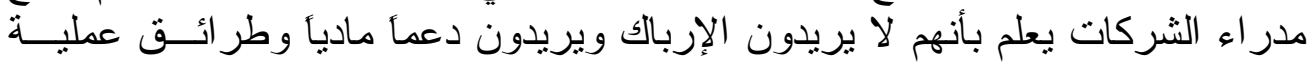
تساعدهم في صنع أفضل القرار ات (Cokins,2001,43).

\section{المحور الرابع: عرض نتائج الاستبانة وتحليلها}

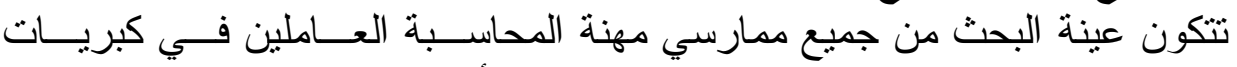
الثركات الصناعية في مدينة الموصل، إذ نم نوزيع الأستبانات بطريقة العينة العينة العشو ائية

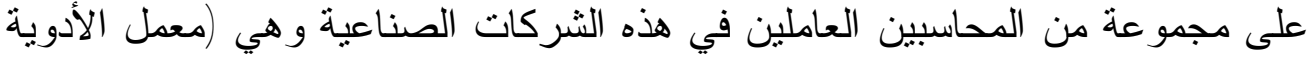

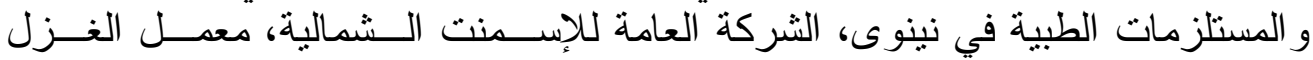

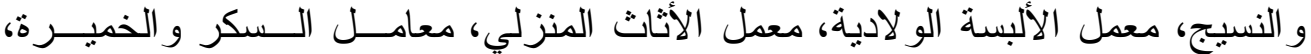

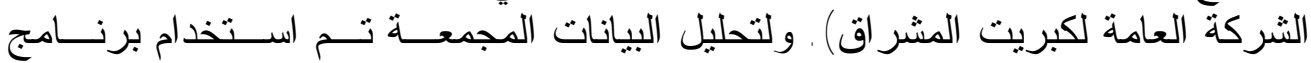
(Excel)

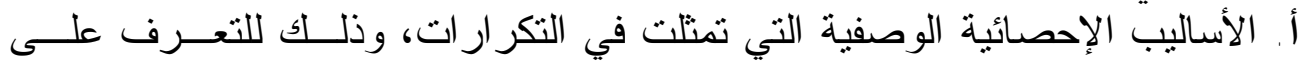
خصائص عينة البحث و التكرار الت النسية النسبية لبيان مقدار النسبة المئوية لكل فئة من

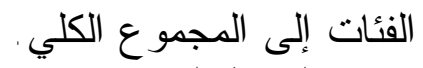

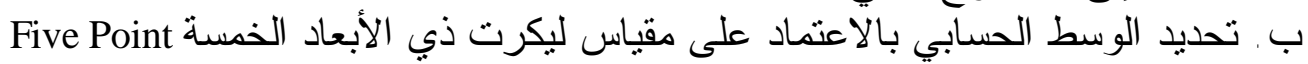

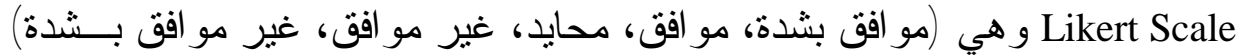

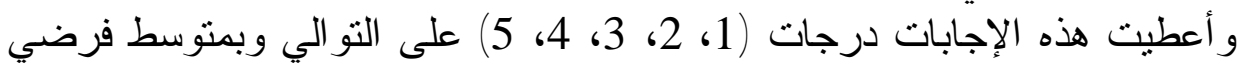

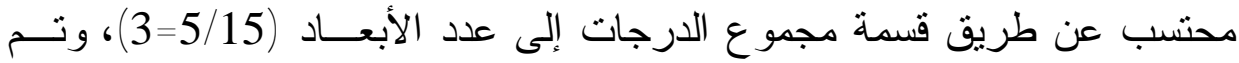

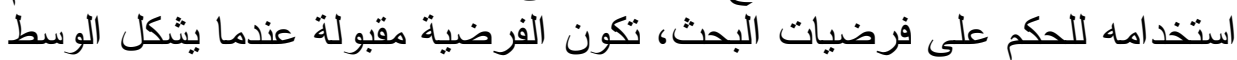

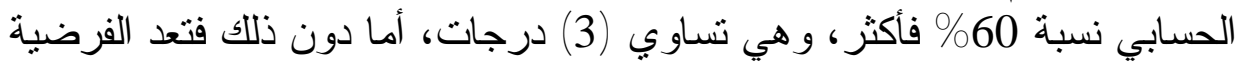
ت. الانحر اف المعياري وتم استخدامه من أجل التعرف على مقــدار التـشتـت فـي الإجابات حول الوسط الحسابي. 
أولاً - تحليل خصائص عينة البحث

\begin{tabular}{|c|c|c|c|c|c|}
\hline \multicolumn{6}{|c|}{ 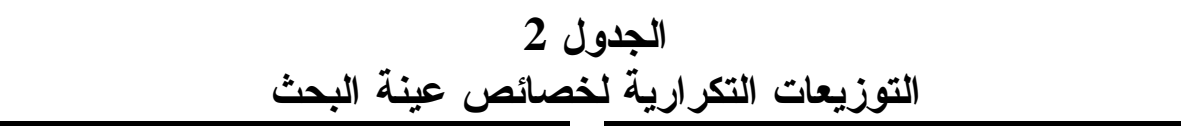 } \\
\hline$\%$ & التكرار & الاختصاص الدقيق & $\%$ & الت التكر ار & التحصيل العلمي \\
\hline 57.9 & 22 & محاسب مالي & 10.5 & 4 & إعدادية \\
\hline 0 & 0 & محاسب إداري & 26.3 & 10 & دبلوم \\
\hline 23.7 & 9 & محاسب تكاليف & 63.2 & 24 & بكالوريوس \\
\hline 18.4 & 7 & مدقق حسابات & 0 & 0 & شهادة عليا \\
\hline$\% 100$ & 38 & المجموع & $\% 100$ & 38 & المجموع \\
\hline$\%$ & التكر ار & عدد سنوات الخبرة & $\%$ & التكر ار & الارجة الوظيفية \\
\hline 23.7 & 9 & 1 - 5 سنة & 21.1 & 8 & معاون محاسب \\
\hline 23.7 & 9 & 10- 5 & 26.3 & 10 & محاسب \\
\hline 18.4 & 7 & $15-10$ & 15.8 & 6 & محاسب أقدم \\
\hline 13.1 & 5 & 20- 15 & 36.8 & 14 & مدير حسابات \\
\hline 21.1 & 8 & 20 - سنة فأكثر & $\% 100$ & 38 & المجموع \\
\hline$\% 100$ & 38 & المجموع & & & \\
\hline
\end{tabular}

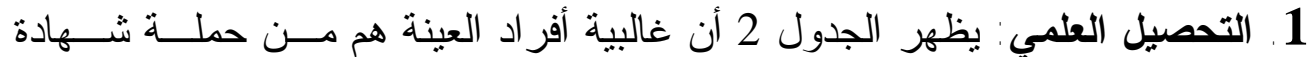

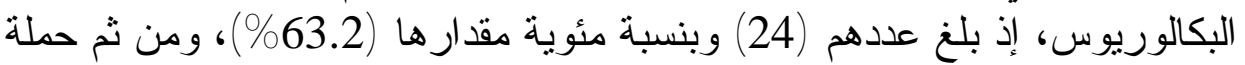

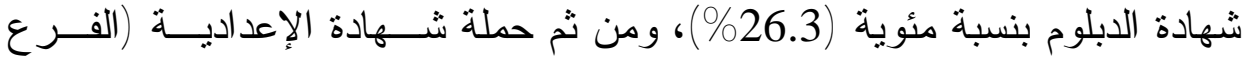

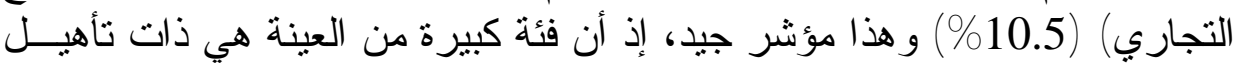

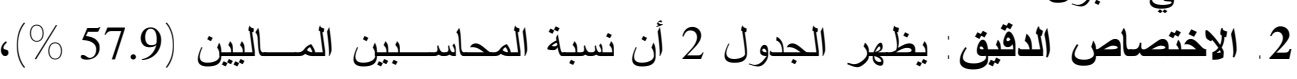

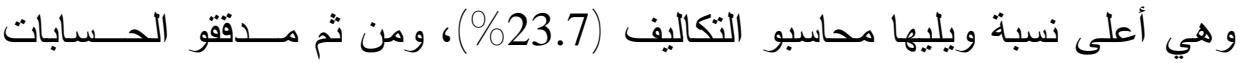

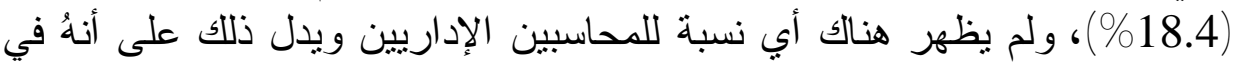

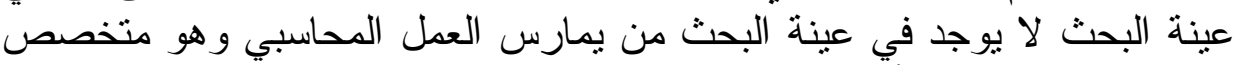

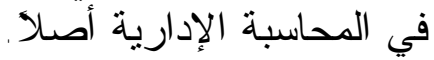




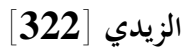

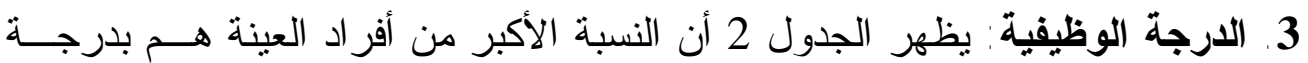

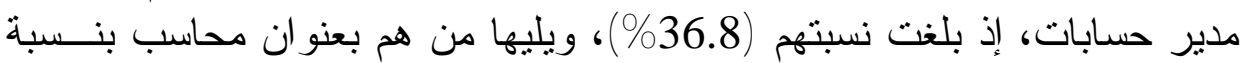

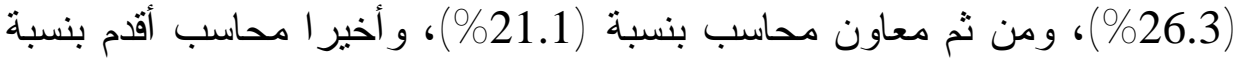
. (\% 15.8)

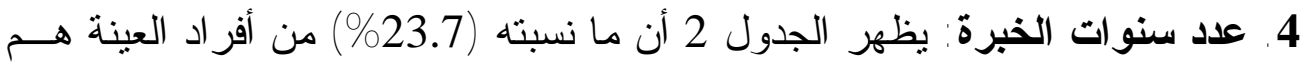

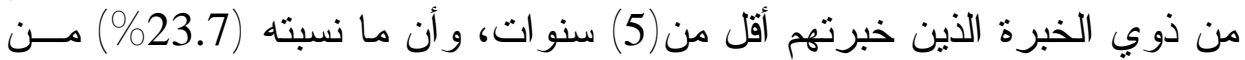

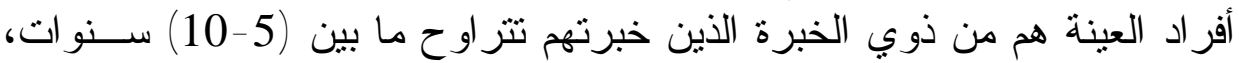

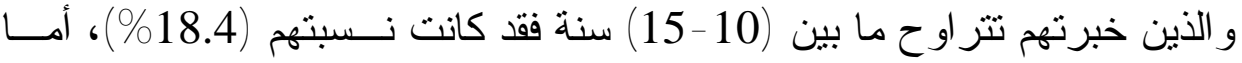

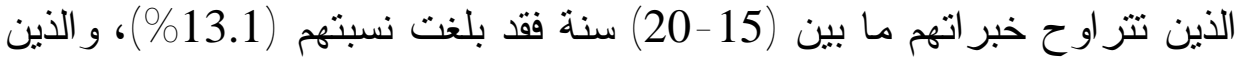

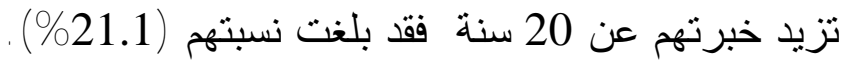

ثثانياً - التحديات المرتبطة بتطبيق الأساليب الحديثة في المحاسبة الإدارية

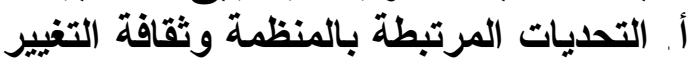

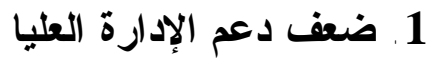

تم قياس هذا المتغير من خلال الأسئلة المبينة في الجدول 3 وذللك بإيجاد كل من الوسط الحسابي و الانحر اف المعياري لإجابات أفر اد عينة البحث وكالآتي:

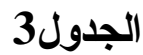

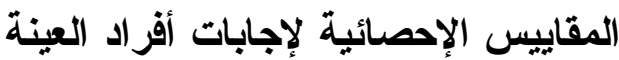

حول التحديات المتعلقة بلدع الإدارة العليا لتطبيق الأساليب الحديثة الإبية

\begin{tabular}{|c|c|c|c|c|c|c|c|c|c|c|c|c|}
\hline \multirow{2}{*}{ 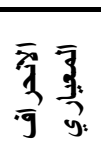 } & \multirow{2}{*}{ الحسابي } & \multicolumn{2}{|c|}{ غير موافق } & \multicolumn{2}{|c|}{ غير موافق } & \multicolumn{2}{|c|}{ محايد } & \multicolumn{2}{|c|}{ مو افق } & \multicolumn{2}{|c|}{ موافق بثدة } & /لإجابة \\
\hline & & $\%$ & عدد & $\%$ & عدد & $\%$ & عدد & $\%$ & عدد & $\%$ & عدد & 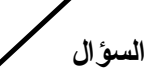 \\
\hline 0.963 & 3.421 & 0 & 0 & 23.7 & 9 & 21 & 8 & 44.8 & 17 & 10.5 & 4 & 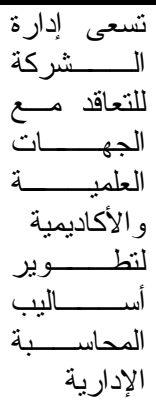 \\
\hline 0.993 & 3.526 & 0 & 0 & 26.7 & 9 & 13.15 & 5 & 50 & 19 & 13.15 & 5 & الــــــــر إدركة \\
\hline
\end{tabular}




\begin{tabular}{|c|c|c|c|c|c|c|c|c|c|c|c|c|}
\hline \multirow{2}{*}{$\begin{array}{l}\bar{y} \\
\bar{y} \\
\bar{y}\end{array}$} & \multirow{2}{*}{ الحسابي } & \multicolumn{2}{|c|}{ غير مو افقى } & \multicolumn{2}{|c|}{ غير موافق } & \multicolumn{2}{|c|}{ محايد } & \multicolumn{2}{|c|}{ مو افق } & \multicolumn{2}{|c|}{ موافق بثدة } & / الإجابة / مقياس \\
\hline & & $\%$ & عدد & $\%$ & عدد & $\%$ & عدد & $\%$ & عدد & $\%$ & عدد & السؤال \\
\hline & & & & & & & & & & & & 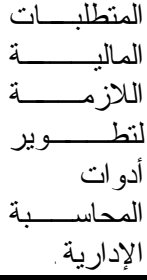 \\
\hline 1.024 & 3.052 & 7.9 & 3 & 21.1 & 8 & 34.2 & 13 & 31.6 & 12 & 5.2 & 2 & 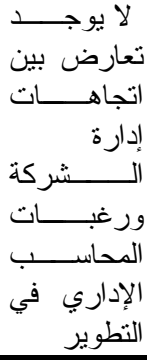 \\
\hline 0.992 & 3.552 & 0 & 0 & 18.4 & 7 & 26.4 & 10 & 36.8 & 14 & 18.4 & 7 & 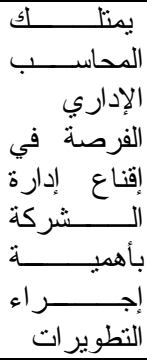 \\
\hline 0.781 & 3.368 & 2.6 & 1 & 13.1 & 5 & 31.7 & 12 & 47.3 & 18 & 5.3 & 2 & 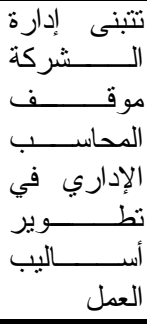 \\
\hline 0.968 & 3.384 & & & & & & & & & & & العنوسط \\
\hline
\end{tabular}

يبين الجدول 3 التحديات المتعلقة بدعم الإدارة العليا لتطبيق الأساليب الحديثــة طبقأ لمنوسطها الحسابي، كما يبين أيضاً نسبة المستجيبين تحت كل درجة من درجات الإن 
الزيدي [324

المو افقة على هذه التحديات، فضلا عن الانحر اف المعياري للإجابات لكل تحدٍ علـى حدة.

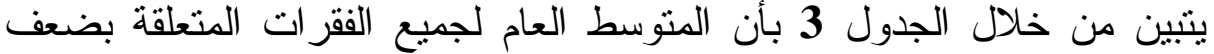

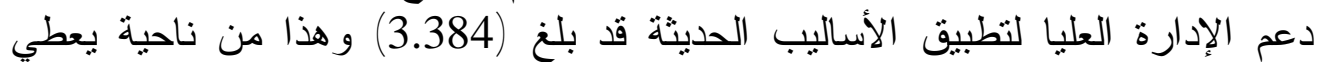

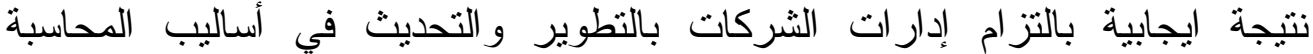

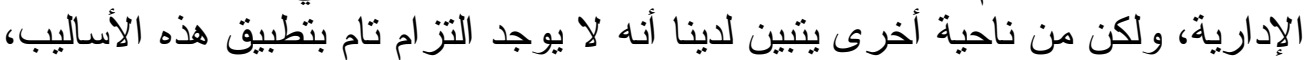

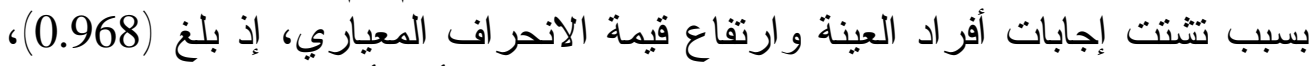

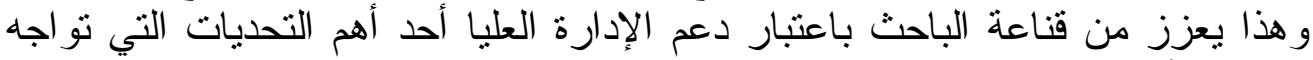
تطبيق الأساليب الحديثة.

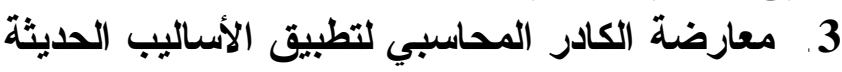

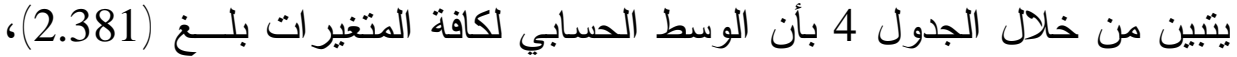

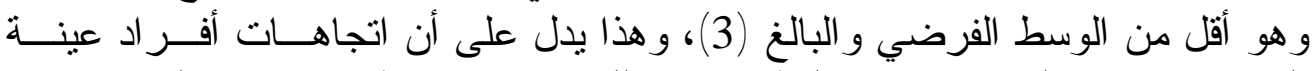

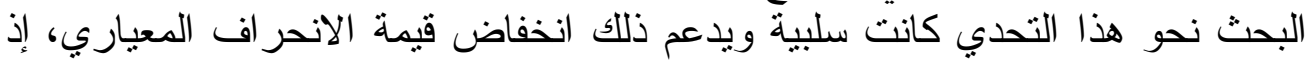

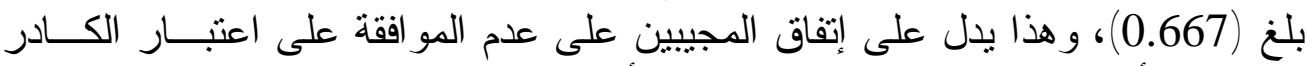

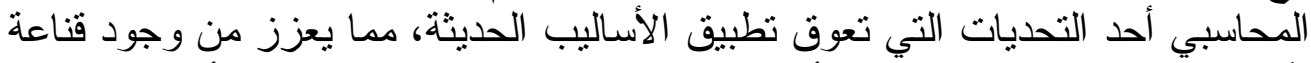
بأن المحاسبين ير غبون بتطوير أدو اتهم بالثكل الذي يحقق لهم مساهمة أكبر في إدارة

\begin{tabular}{|c|c|c|c|c|c|c|c|c|c|c|c|c|}
\hline & & & يوين & فرادر & خة & دول & $\sqrt{2}$ & ـ الإلإ & $\mathbf{2}$ & & & \\
\hline \multirow[t]{2}{*}{ المعياري } & \multirow[t]{2}{*}{ الحسابي } & \multicolumn{2}{|c|}{ مو غيّت } & \multicolumn{2}{|c|}{ غير موافق } & \multicolumn{2}{|c|}{ محايد } & \multicolumn{2}{|c|}{ مو افق } & \multicolumn{2}{|c|}{ مو افقدة } & \\
\hline & & $\%$ & عدد & $\%$ & عدد & $\overline{\%}$ & عدد & $\%$ & عدد & $\%$ & عدد & السؤال \\
\hline 0.708 & 2.394 & 5.3 & 2 & 57.9 & 22 & 28.9 & 11 & 7.9 & 3 & 0 & 0 & الطية معاسبي الحبدي الحالي \\
\hline 0.624 & 2.368 & 5.2 & 2 & 55.2 & 21 & 36.9 & 14 & 2.7 & 1 & 0 & 0 & 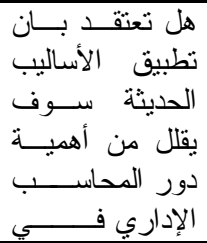 \\
\hline
\end{tabular}




\begin{tabular}{|l|l|l|l|l|l|l|l|l|l|l|l|l|}
\hline & & & & & & & & & & & & \\
\hline 0.667 & 2.381 & & & & & & & & & & & الثركة العنو \\
\hline
\end{tabular}

3. عدم تعاون المستويات الأخرى في تطبيق الأساليب الحديثة

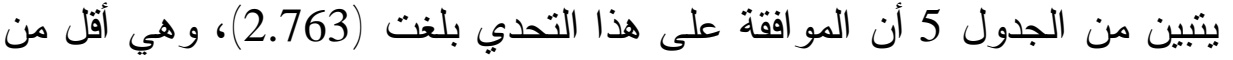

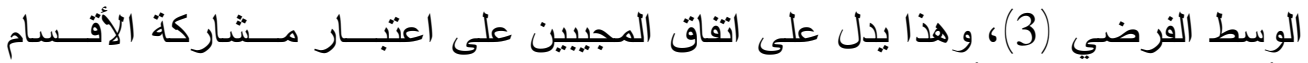

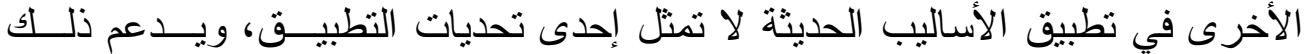

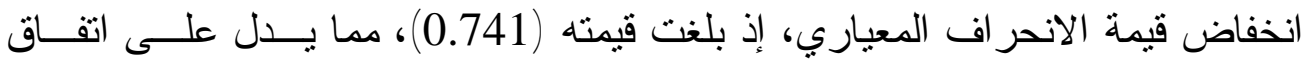

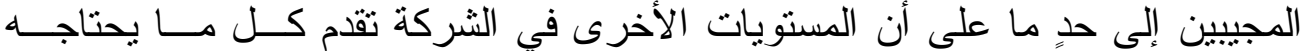
المحاسب الإداري أو محاسب التكاليف من معلومات تسهم في تطوير أساليب العمل.

\section{الجدول 5}

المقاييس الإحصائية لإجابات أفراد المئول العينة حول

التحديات المتعلقة بمشاركة المستويات الأخرى في تطبيق الأساليب الحديثة الإيثة

\begin{tabular}{|c|c|c|c|c|c|c|c|c|c|c|c|c|}
\hline \multirow{2}{*}{ المعياري } & \multirow{2}{*}{ الحسابط } & \multicolumn{2}{|c|}{ غير مو افق } & \multicolumn{2}{|c|}{ غير موافق } & \multicolumn{2}{|c|}{ محايد } & \multicolumn{2}{|c|}{ مو افق } & \multicolumn{2}{|c|}{ بثودة } & مقيا \\
\hline & & $\%$ & عدد & $\%$ & عدد & $\%$ & عدد & $\%$ & عدد & $\%$ & عدد & السؤوآل \\
\hline 0.741 & 2.763 & 2.6 & 1 & 34.3 & 13 & 47.3 & 18 & 15.8 & 6 & 0 & 0 & 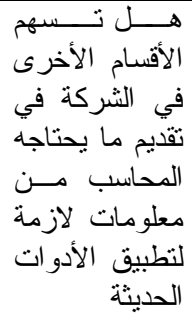 \\
\hline 0.741 & 2.763 & & & & & & & & & & & المتوسط العام \\
\hline
\end{tabular}

إن إجابات أفر اد عينة البحث عن هذا المحور تؤكد أن ثقافة التغيير بمسستوياتها

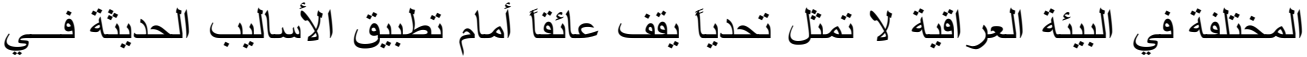

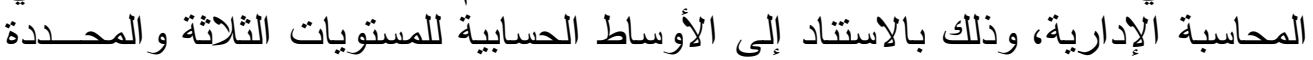

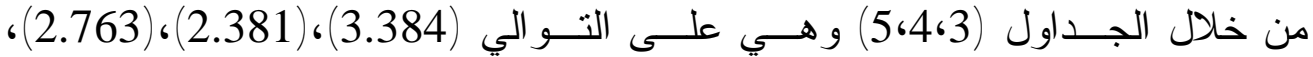

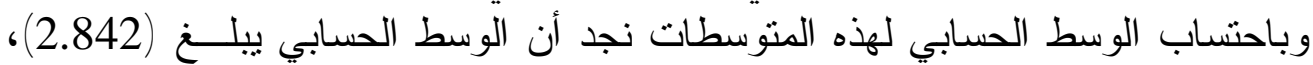

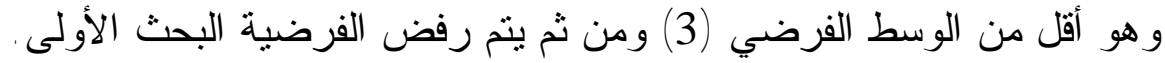


[326] الزيدي [3

ب. التحديات المتعلقة بقلة الخبرة ونقص الكادر المدرب

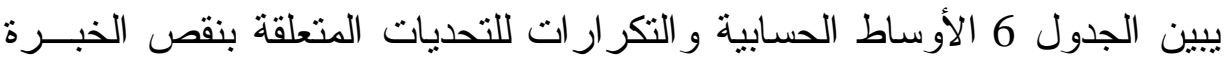

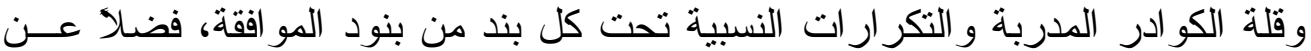
الانحر افات المعيارية لكل تحدٍ على حدة.

\begin{tabular}{|c|c|c|c|c|c|c|c|c|c|c|c|c|}
\hline & & كرب & 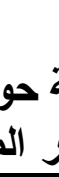 & () & رنق & 10 & ائيً & كقا & يبير اله & تحديا & & \\
\hline الاتحراف & الوسط & إفق & غير بث & & & & & فق & & بثدة & & $\omega$ \\
\hline المعياري & الحسابي & $\%$ & عدد & $\%$ & عدد & $\%$ & عدد & $\%$ & عدد & $\%$ & عدد & \\
\hline 0.613 & 3.789 & 0 & 0 & 5.2 & 2 & 15.9 & 6 & 73.7 & 28 & 5.2 & 2 & 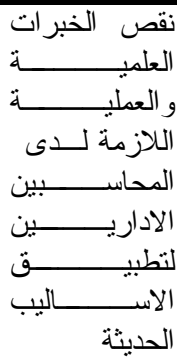 \\
\hline 0.929 & 3.631 & 2.6 & 1 & 13.1 & 5 & 13.1 & 5 & 60.7 & 23 & 10.5 & 4 & 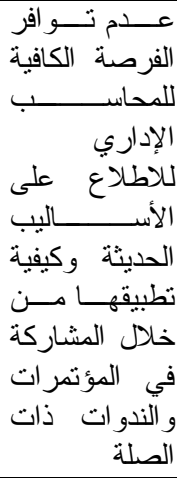 \\
\hline 0.855 & 3.710 & 0 & 0 & 13.1 & 5 & 15.9 & 6 & 57.9 & 22 & 13.1 & 5 & 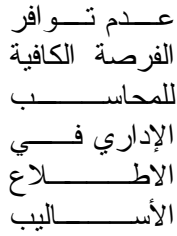 \\
\hline
\end{tabular}




\begin{tabular}{|c|c|c|c|c|c|c|c|c|c|c|c|c|}
\hline \multirow{2}{*}{ المعياري } & \multirow{2}{*}{ الحسابي } & \multicolumn{2}{|c|}{ غير مو افقى } & \multicolumn{2}{|c|}{ غير موافق } & \multicolumn{2}{|c|}{ محايد } & \multicolumn{2}{|c|}{ موافق } & \multicolumn{2}{|c|}{ موافق بشدة } & (1) \\
\hline & & $\%$ & عدد & $\%$ & عدد & $\%$ & عدد & $\%$ & عدد & $\%$ & عدد & السؤال \\
\hline & & & & & & & & & & & & 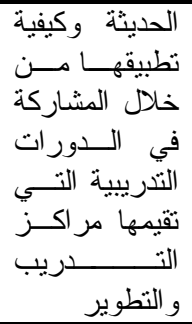 \\
\hline 0.907 & 3.578 & 2.6 & 1 & 7.9 & 3 & 31.6 & 12 & 44.9 & 17 & 13.1 & 5 & 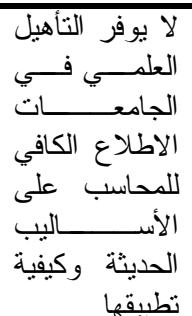 \\
\hline 0.723 & 3.947 & 0 & 0 & 5.2 & 2 & 13.1 & 5 & 63.2 & 24 & 18.5 & 7 & 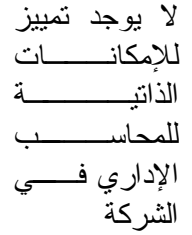 \\
\hline 0.805 & 3.731 & & & & & & & & & & & المتوسط العام \\
\hline
\end{tabular}

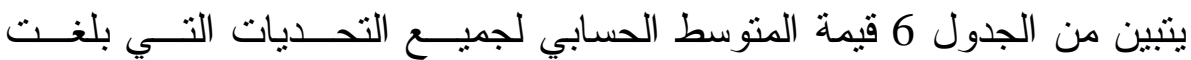

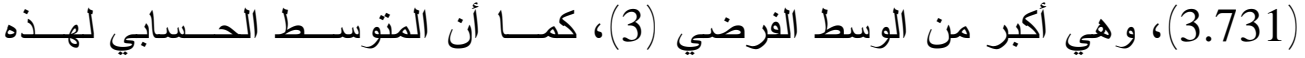

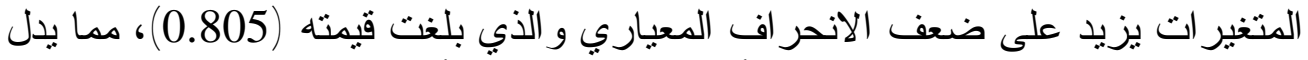

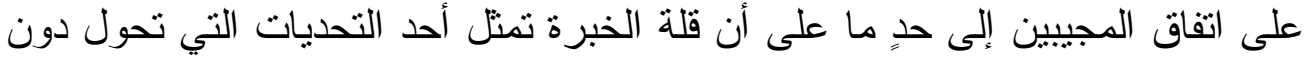

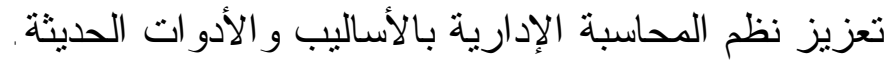

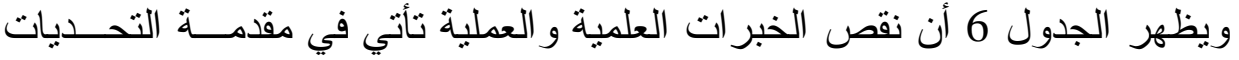

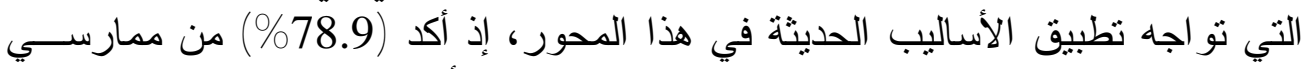

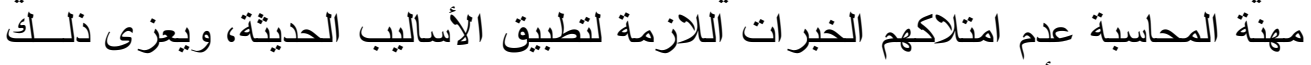

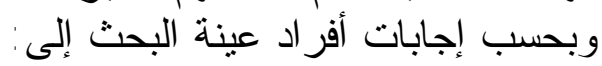

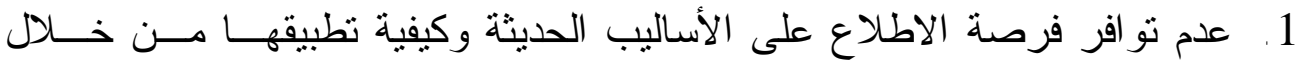
المشاركة في المؤتمر ات والندو ات ذات الصلة، إذ أكد (71.2\%) من أفر اد العينة 


\section{الزيدي [328]}

على أهمية هذا التحدي، وبلغت درجة المو افقة عليه (3.631) وبانحر اف معياري

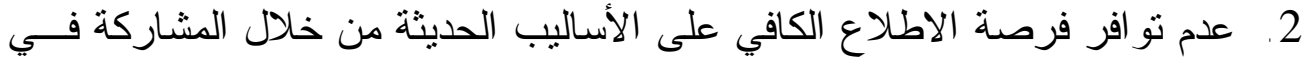

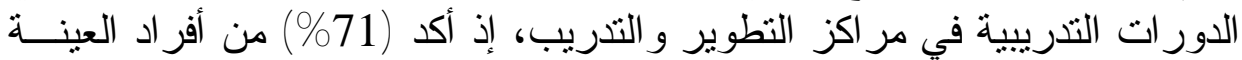

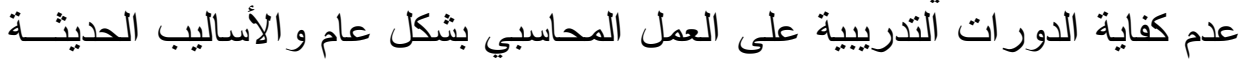

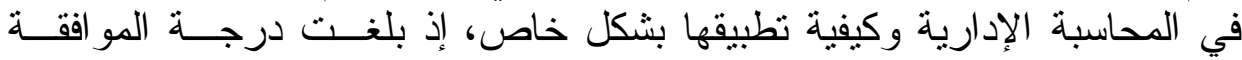

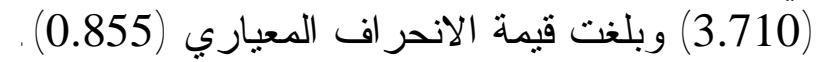

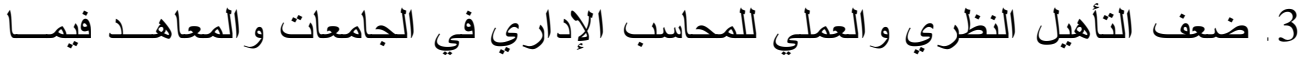

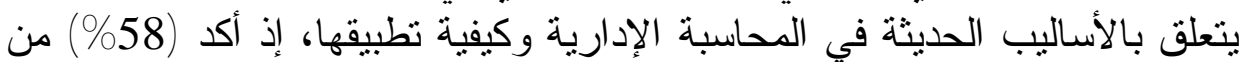

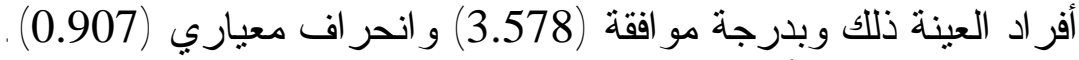

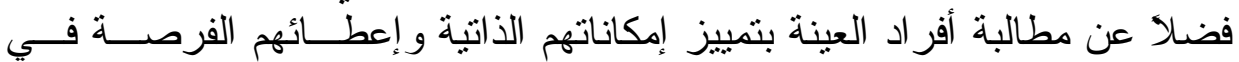

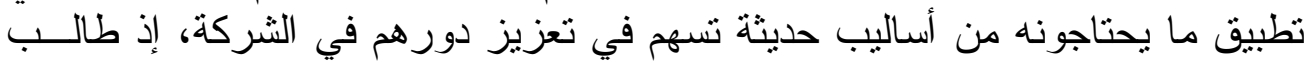

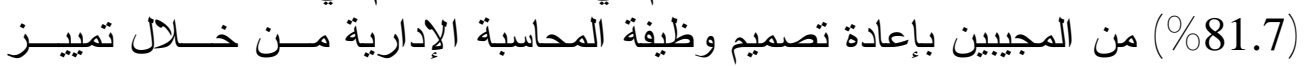
الإمكانات الذاتية للمحاسبين، ولعل أحد أسباب ذلاعن أن أن هناك الكثير من الذين الذين يمارسون

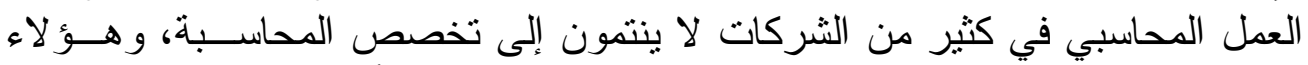

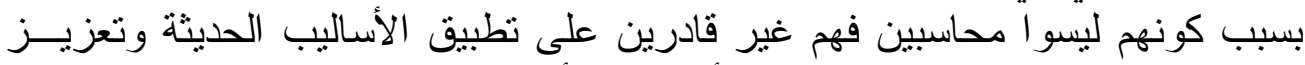
نظم المحاسبة الإدارية في شركاتهم بالأدو ات و الأساليب الحديثة فئنة

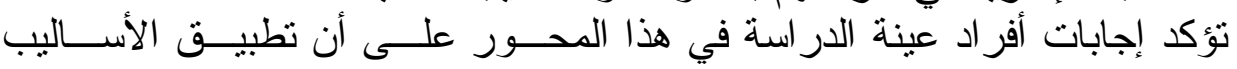

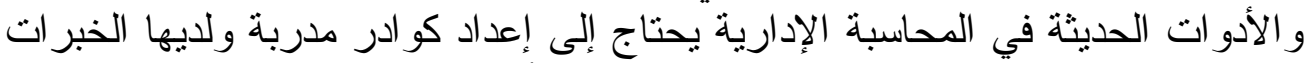

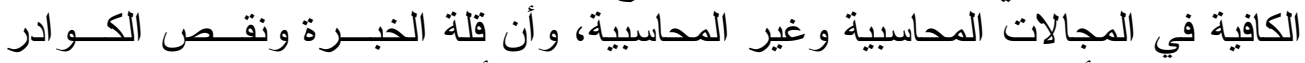

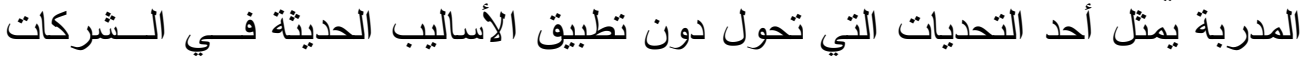
العر اقية وهذا ما يثبت فرضية الَّبث البحت الثانية.

ت. التحديات المتعلقة بقياس المنفعة للأدوات الحديثة

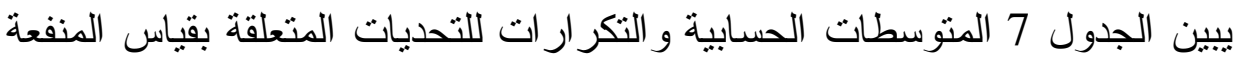

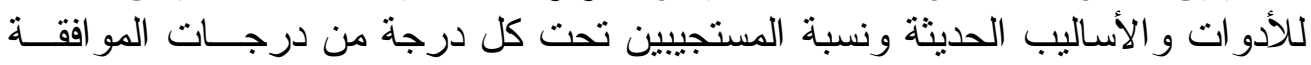

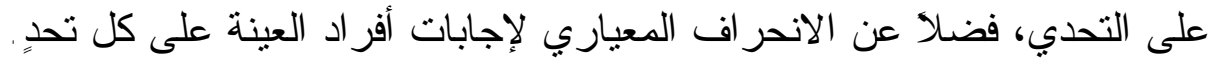

\section{الجدول 7}

المقاييس الإحصائية لإجابات أفراد العينة حول

التحديات المتعلقة بقياس الإندائة لإبات المنفة للأدوات العديثة حولة 


\begin{tabular}{|c|c|c|c|c|c|c|c|c|c|c|c|c|}
\hline \multirow{2}{*}{$\frac{\bar{y}}{\bar{y}} \stackrel{\overline{3}}{9}$} & \multirow[t]{2}{*}{ الحسابي } & \multicolumn{2}{|c|}{ مو غير بشد } & \multicolumn{2}{|c|}{ غير موافق } & \multicolumn{2}{|c|}{ محايل } & \multicolumn{2}{|c|}{ موافق } & \multicolumn{2}{|c|}{ موافق بشدة } & \multirow[b]{2}{*}{ السؤ ال } \\
\hline & & $\%$ & عدد & $\%$ & عدد & $\%$ & عدد & $\%$ & عدد & $\%$ & عدد & \\
\hline 0.739 & 4.078 & 0 & 0 & 2.6 & 1 & 15.8 & 6 & 52.6 & 20 & 29 & 11 & 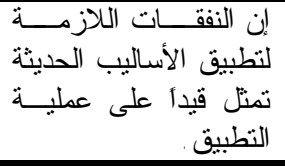 \\
\hline 0.664 & 3.921 & 0 & 0 & 2.6 & 1 & 18.4 & 7 & 63.2 & 24 & 15.8 & 6 & أنشاط الطبيق ما يتلاءه من الألتصادية \\
\hline 0.753 & 4.105 & 0 & 0 & 5.2 & 2 & 7.9 & 3 & 57.9 & 22 & 29 & 11 & تصميم وظيفة الإلكاسبة الإعـادة \\
\hline 0.655 & 4.21 & 0 & 0 & 2.6 & 1 & 5.2 & 2 & 60.7 & 23 & 31.5 & 12 & 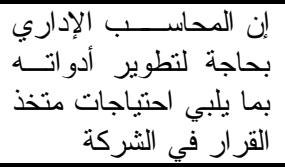 \\
\hline 0.703 & 4.078 & & & & & & & & & & & المنوسط العام \\
\hline
\end{tabular}

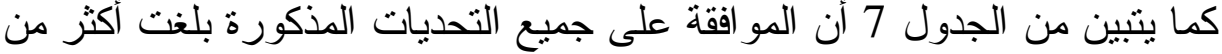

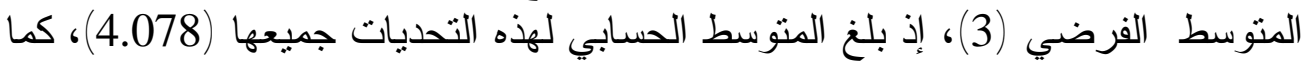
بلغت قيمة الانحر اف المعياري (303)، (30.703، مما بدل على قلة تباين الآراء حول المو افقة على هذه التحديات . ويبين الجدول 7 أيضاً، أن القيمة التي سوف تضيفها الأساليب الحديثة قد تبــرر

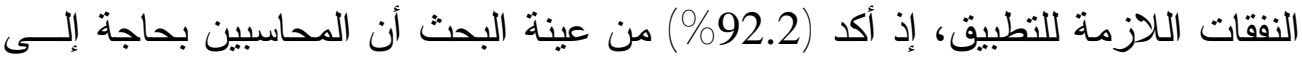

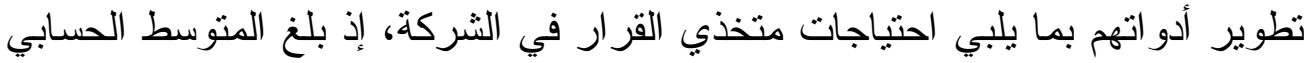

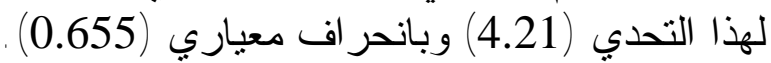

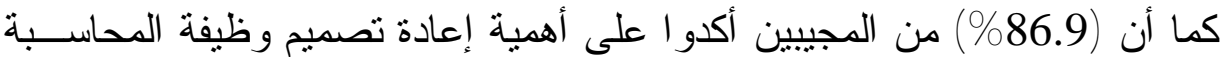

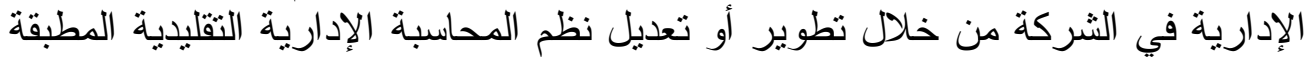

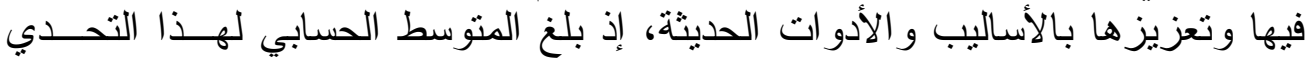
جميعها (4.105) وبانحر اف معياري (0.753) . 
[330] الزيدي

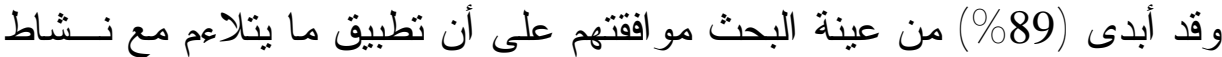

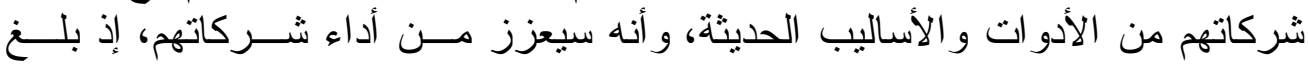

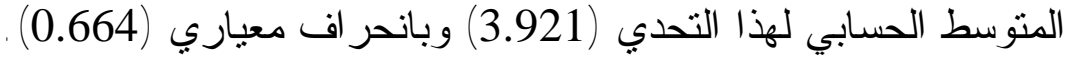

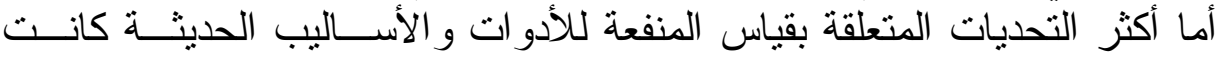

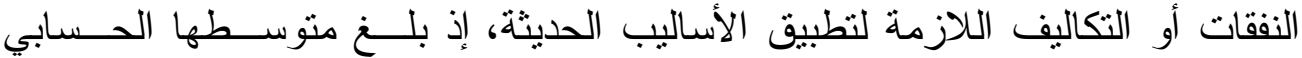

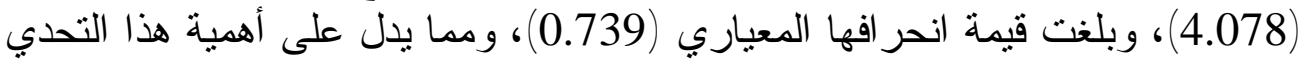

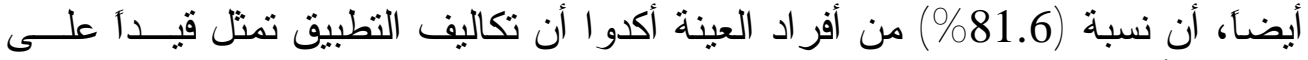
تطبيق الأساليب الحديثة.

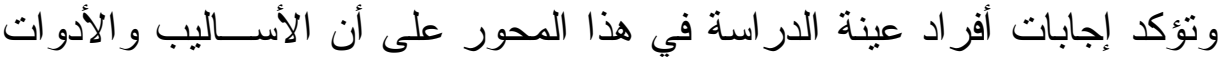

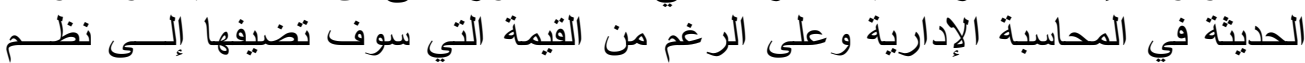

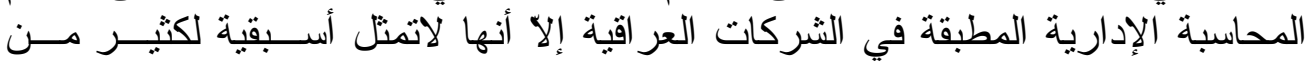

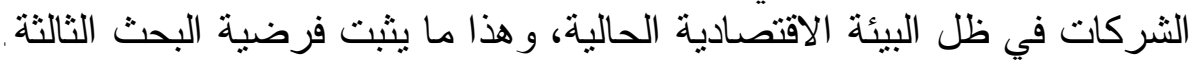

ث. التحديات المتعلقة بملاعمة بحوث المحاسبة الإدارية

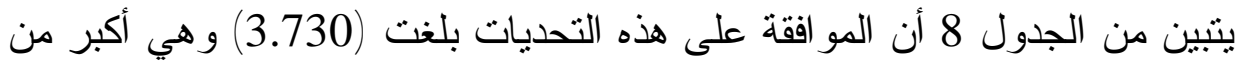

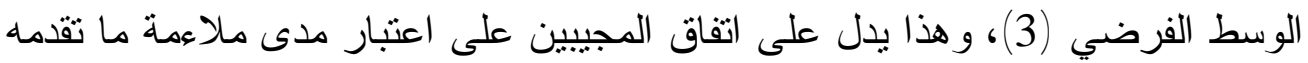

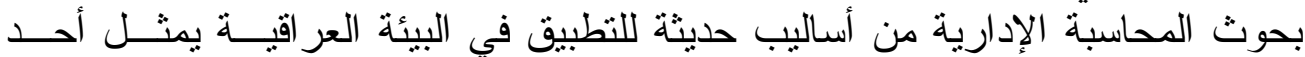

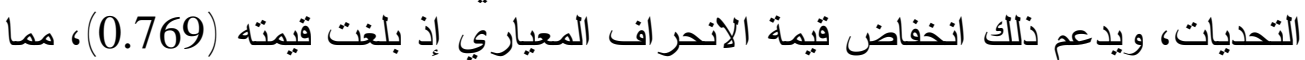
يدل على اتفاق المجييين إلى حلٍٍ ما على هذا التحدي. التحدي.

\section{الجدول 8}

المقاييس الإحصائية لإجابات أفر اد العينة حول

التحديات المتعلقة بملاعمة بحوث الإبات المحاسبة الإدارية حرلة

\begin{tabular}{|c|c|c|c|c|c|c|c|c|c|c|c|c|}
\hline \multirow[t]{2}{*}{ الالمعياري } & \multirow[t]{2}{*}{ الحسابي } & \multicolumn{2}{|c|}{ موافقي } & \multicolumn{2}{|c|}{ غير موافق } & \multicolumn{2}{|c|}{ محايد } & \multicolumn{2}{|c|}{ موافق } & \multicolumn{2}{|c|}{ موافق بثدة } & \multirow{2}{*}{ السؤل /لقيس الإجابة } \\
\hline & & $\%$ & عدد & $\%$ & عدد & $\%$ & عدل. & $\%$ & عدد & $\%$ & عال & \\
\hline 0.815 & 3.578 & 0 & 0 & 13.1 & 5 & 23.7 & 9 & 55.2 & 21 & 7.9 & 3 & 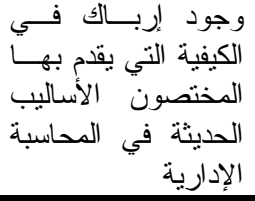 \\
\hline 0.815 & 3.578 & 0 & 0 & 13.1 & 5 & 23.7 & 9 & 55.2 & 21 & 7.9 & 3 & 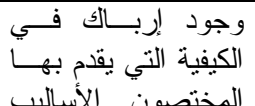 \\
\hline
\end{tabular}




\begin{tabular}{|c|c|c|c|c|c|c|c|c|c|c|c|c|}
\hline \multirow[t]{2}{*}{ الالحيراف } & \multirow[t]{2}{*}{ الوسابط } & \multicolumn{2}{|c|}{ بشئ بوافي } & \multicolumn{2}{|c|}{ غير موافق } & \multicolumn{2}{|c|}{ محايد } & \multicolumn{2}{|c|}{ موافق } & \multicolumn{2}{|c|}{ موافق بشدة } & \multirow[b]{2}{*}{ السؤال } \\
\hline & & $\%$ & عدد & $\%$ & علد & $\%$ & عدد & $\%$ & عدد & $\%$ & عدد & \\
\hline & & & & & & & & & & & & الإدارية في المحاسبة \\
\hline 0.880 & 3.473 & 0 & 0 & 18.4 & 7 & 23.7 & 9 & 50 & 19 & 7.9 & 3 & 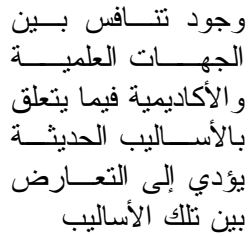 \\
\hline 0.870 & 3.921 & 0 & 0 & 10.5 & 4 & 10.5 & 4 & 55.3 & 21 & 23.7 & 9 & 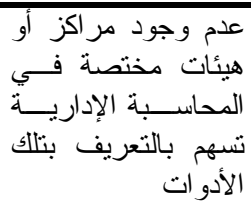 \\
\hline 0.510 & 3.947 & 0 & 0 & 2.6 & 1 & 7.9 & 3 & 81.6 & 31 & 7.9 & 3 & 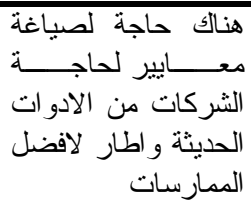 \\
\hline 0.769 & 3.730 & & & & & & & & & & & المتوسط العام \\
\hline
\end{tabular}

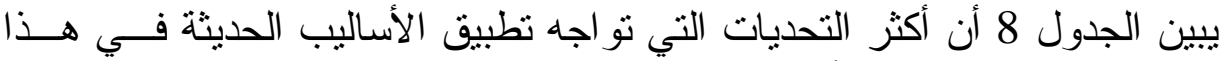

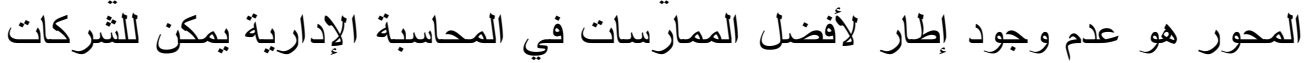
الاسترشاد به في تطوير نظم المحاسبة الإدارية المطبقة فيها، إذ أكد (88.5\%) مسنـن

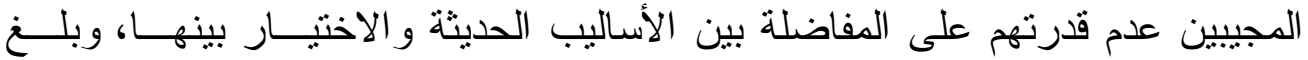

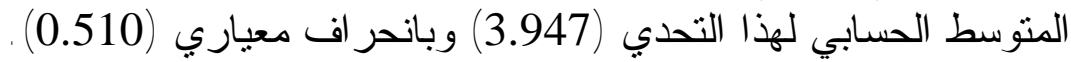

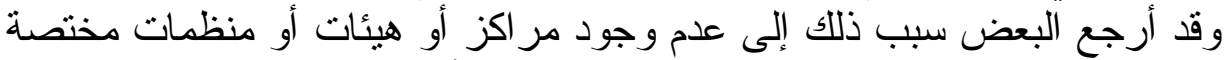
في المحاسبة الإدارية في العراق تسهم في التعريف بالأساليب الحديثة وكيفية تطبيقها

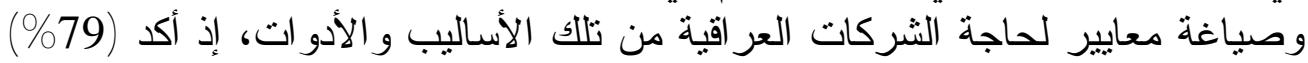

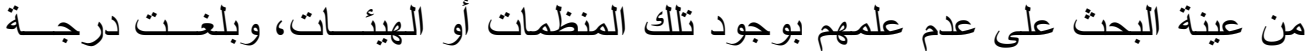

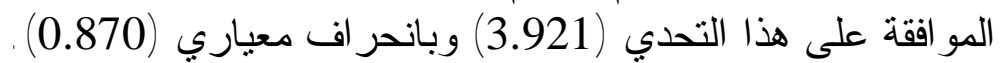
في حين أرجع البعض الآخر أسباب عدم التطبيق إلى الإربالك في طريقة تقـئديم

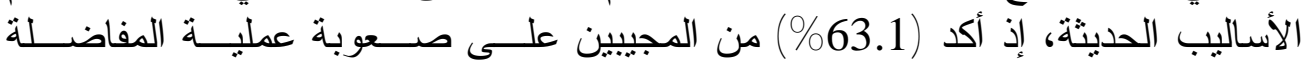

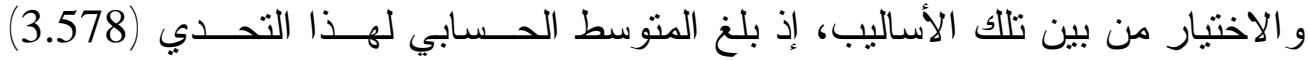
وبإنحر اف معياري (0.815) . 


\section{[332] [ الزيدي}

وقد أبدى (57.9\%) من المجيبين مو افقته على أن المنافسة بين الجهات العلمية

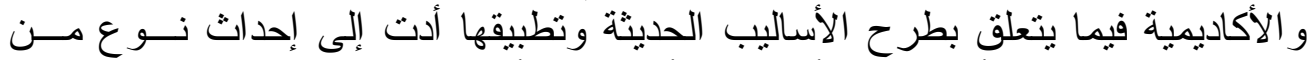

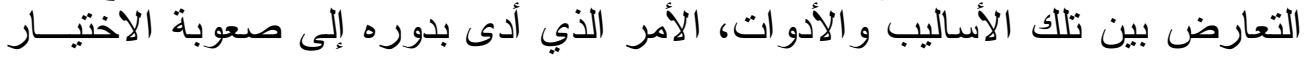
و المفاضلة بينها، وبلغت درجة المو افقة على هذا التحدي (3.473) وبانحر الإن الف معياري

تؤكد إجابات أفر اد عينة الدر اسة في هذا المحور أن عدم وجود مر اكز أو هيئات

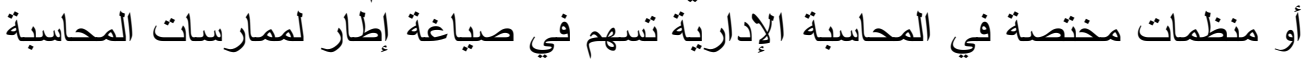

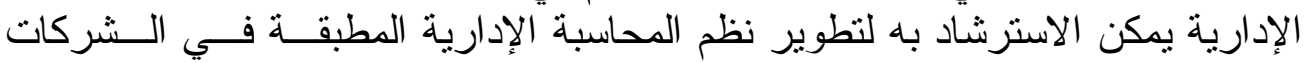

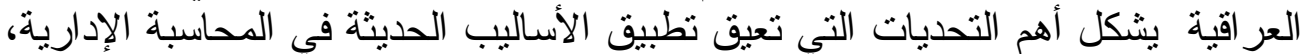

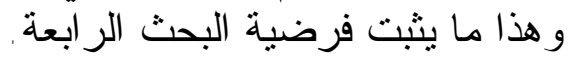

1. إن الأساليب الحديثة هي السمة المميزة لنطور المحاسبة الإدارية وهي نتاج لتنازم منطقي بين التهديدات و الفرص التي تو اجه المنظمات في بيئة الأعمال الحديثة.

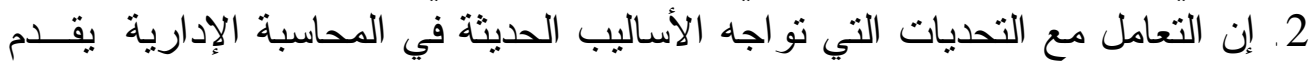

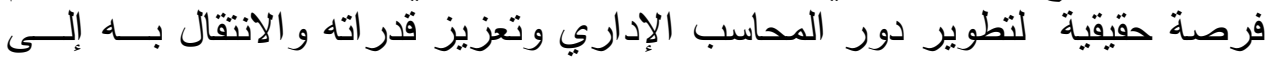

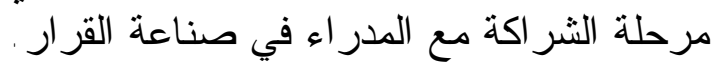
3. إن عدم نو افر الصدلاحيات للتوسع في إجر اءع التحاء التحديثات على نظم المحاسبة الإدارية و التقيد بالتعليمات أدى بالكثير من الثركات العر اقية إلى التأخر في تطبيق الأساليب الحديثة. 4. إن عدم وجود أقسام للمحاسبة الإدارية في الثركات العر اقية أدى إلى قيام الأقـسام

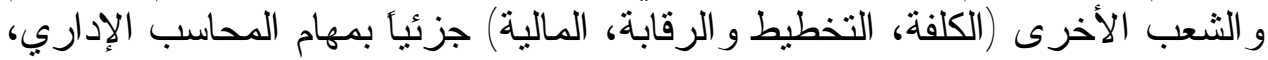
وقد أضاف ذلك تحدياً جديداً أمام تطبيق الأساليب الحديثة في النية المحاسبة الإدارية.

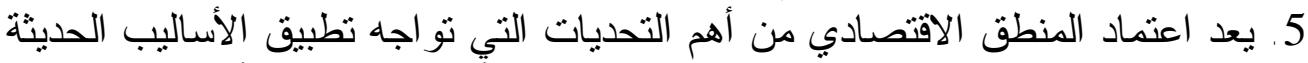

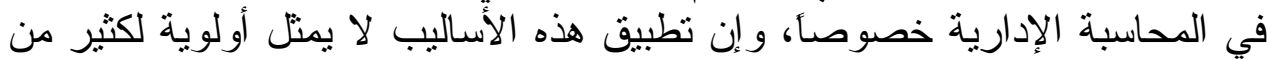

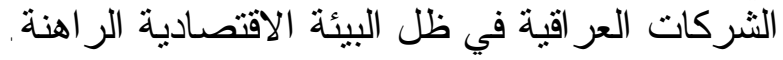

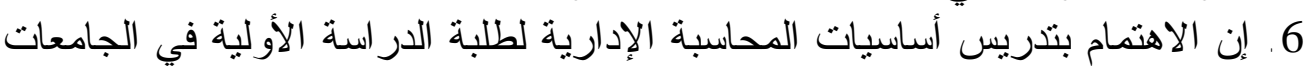

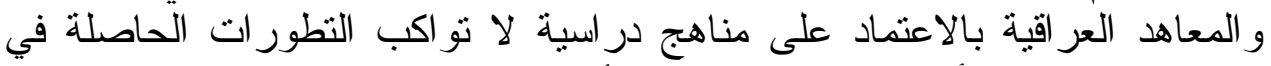

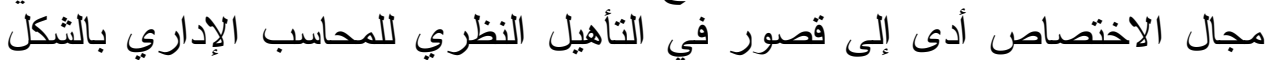
الذي أثز في قدرته على نطبيق الأساليب الحديثة. 
7.عدم مو اكبة ممارسي المهنة للمستجدات في المحاسبة الإدارية من خلال المشاركة

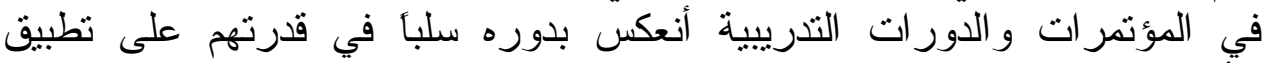
الآساليب الحديثة.

8. عدم وجود مر اكز أو هيئات أو منظمات عر اقية مختصة في المحاسبة الإدارية على الإئ

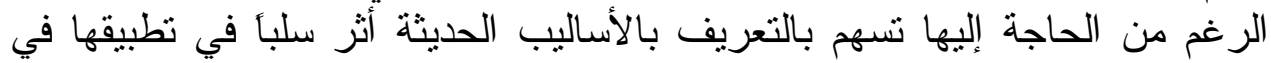

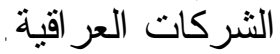

ثانياً - التوصيات

1. يؤكد البحث على نوعية المحاسبين الإداريين المطلوبين لبيئة الأعمال الحديثة فهر

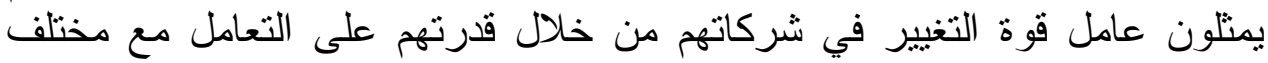

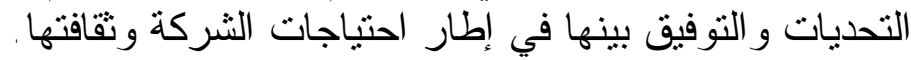

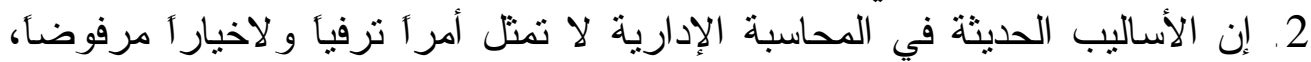

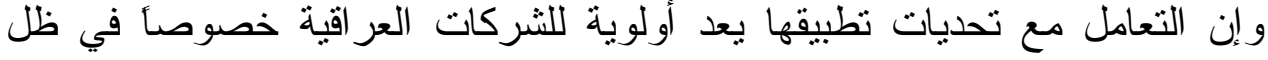

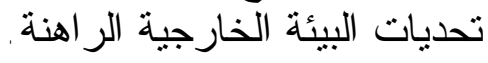
3. على الثركات العر اقية إعطاء اهتمام أكبر لوظيفة الرية المحاسبة الإدارية و إنثاء أقسام

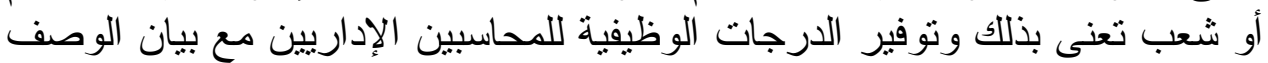

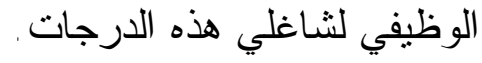
4. ضرورة قيام الجهات العلمية والأكاديمية بإعادة تقييم ممارسات المحاسبة الإدارية المطبقة في الثركات العر اقية وصياغة إطار مفاهيمي لأفضل ممارسات المحاسبة الإدارية.

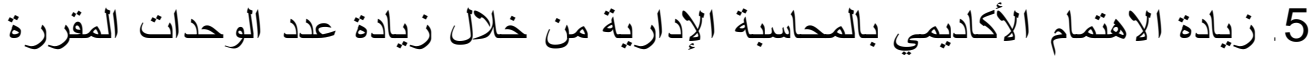

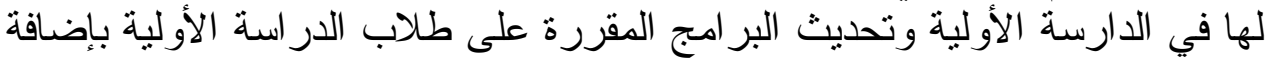

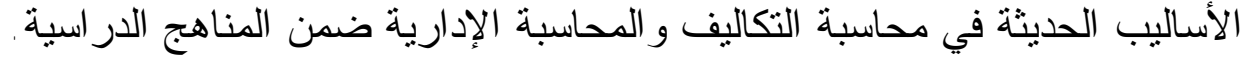

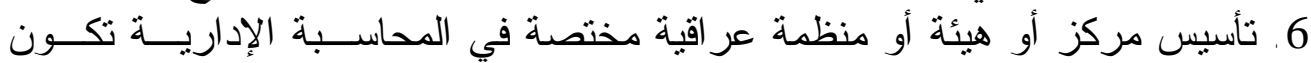

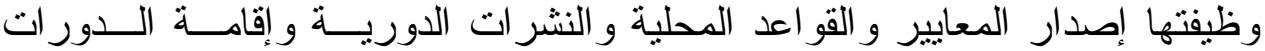

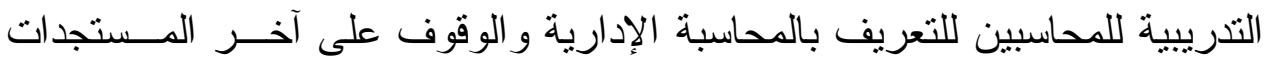

1. Atkinson. A, 1989, "A management accounting constitution", CMA Magazine, vol 63, No 5, JUNE.

2. Burns .J, 2000, " The changing nature of management accounting and the emergence of hybrid accountant", www.ifac.org/articals .

3. Cokins .G, 2001, " A management accounting framework", international Magazine of strategic cost management, vol 1 , No 2 . 


\section{الزيدي [334]}

4. Dminik .T, \& Kudar .R , 1989," Do not throw out the baby with the path water" , CMA Magazine, vol 63, No 6, JULY-AUGUST.

5. Garg .A, Ghosh .D, Hudik .J , Nowaki .C, 2003, "Roles and practices in management accounting today", strategic finance, JULY.

6. International Federation Of Accountants (IFAC), 1998, "Management accounting concepts (IMP 1)", Financial Management \& Management Accounting Committee(FMAC)), MARCH.

7. Kaplan .R.S, 1984," The evolution of management accounting", The Accounting Review, JULY. www.maaw.info.index/managementaccounting.

8. Luther .R , \& Abdel-kader . M, 2006, "Management accounting practices in the UK food industry", CIMA the chartered institute of management accounting, London .

9. Mai .A, Ahmed .F, 2005, "Strategic management accounting practices in the $21^{\text {st }}$ century", The Cost and Management Journal, vol 33, No 4.

10. Ning .Y, 2005, " The development of costing system: a historical perspective", Journal of modern accounting and auditing, vol 1, No 2.

11. Sharma .R, 2000, " From relevance lost to relevance regained : management accounting practices in the new millennium". www.ifac.org/artical

12. Shields .D, Chow .C , Kato .Y, Nakagaw .Y, 1991," Management accounting practices in the U.S and Japan" , Journal of international financial management and accounting, vol 3 , No 1.

13. Steeves .B, 1990, " Trends in management accounting", CMA Magazine, vol 64, No 3,MARCH.

14. www.esnips.com/search/costaccounting, "Basic Cost Concepts". 